NOTICE: this is the author's version of a work that was accepted for publication in Geochimica et Cosmochimica Acta. A definitive version was subsequently published in Geochimica et Cosmochimica Acta 120, 140-157, 2013.

http://dx.doi.org/10.1016/j.gca.2013.06.012

\title{
Phosphate effects on copper(II) and lead(II) sorption to ferrihydrite
}

\author{
Charlotta Tiberg $^{\mathrm{a}^{*}}$, Carin Sjöstedt $^{\mathrm{b}}$, Ingmar Persson $^{\mathrm{c}}$, Jon Petter Gustafsson ${ }^{\mathrm{b}}$
}

a Department of Soil and Environment, Swedish University of Agricultural Sciences (SLU), Box 7014, SE-750 07 Uppsala, Sweden. charlotta.tiberg@slu.se, Tel: +46-18-67 1224 ${ }^{\mathrm{b}}$ Department of Land and Water Resources Engineering, Royal Institute of Technology (KTH), Teknikringen 76, SE-100 44 Stockholm, Sweden. C. Sjöstedt: carinsj@kth.se, J. P. Gustafsson: gustafjp@kth.se

${ }^{c}$ Department of Chemistry, Swedish University of Agricultural Sciences (SLU), SE-750 07

Uppsala, Sweden, ingmar.persson@ @ slu.se

*corresponding author 


\begin{abstract}
Transport of lead(II) and copper(II) ions in soil is affected by the soil phosphorus status. Part of the explanation may be that phosphate increases the adsorption of copper(II) and lead(II) to iron (hydr)oxides in soil, but the details of these interactions are poorly known. Knowledge about such mechanisms is important, for example, in risk assessments of contaminated sites and development of remediation methods. We used a combination of batch experiments, extended X-ray absorption fine structure (EXAFS) spectroscopy and surface complexation modeling with the three-plane CD-MUSIC model to study the effect of phosphate on sorption of copper(II) and lead(II) to ferrihydrite. The aim was to identify the surface complexes formed and to derive constants for the surface complexation reactions. In the batch experiments phosphate greatly enhanced the adsorption of copper(II) and lead(II) to ferrihydrite at $\mathrm{pH}<6$. The largest effects were seen for lead(II).
\end{abstract}

Based on interpretation of the EXAFS spectra edge-sharing bidentate copper(II) or lead(II) complexes predominated in the single-sorbate systems with ferrihydrite. Lead(II) EXAFS spectra suggested a distinct change of coordination in the presence of phosphate, i.e. the signal from edge-sharing complexes diminished and a longer $\mathrm{Pb}^{\cdots}$ Fe distance appeared at about 4 A. A similar, but less pronounced, pattern was observed for copper(II). Based on the results from interpretation of EXAFS spectra and surface complexation modeling with the CD-MUSIC model the enhanced sorption in presence of phosphate was most satisfactorily explained by the appearance of ternary metal-phosphate complexes in which the metal interacts directly with the surface.

In conclusion, geochemical models used for simulating trace element behavior in acidic environments seem to require ternary metal-phosphate surface complexes to properly describe partitioning of metals between solution and the solid phase. 


\section{INTRODUCTION}

Elevated concentrations of phosphate can retard transport of copper(II) and lead(II) in soil. The magnitude and durability of this effect is of special interest in for example risk assessments of contaminated soils and development of soil remediation methods where phosphate is used as a stabilizing agent. The possibility to use phosphate amendments to immobilize lead(II) in remediation of contaminated soils has been tested in pilot projects (Ma el al., 2008; Cao et al., 2002).

The promoting effect of phosphate on lead(II) immobilization has mainly been attributed to the formation of lead(II) phosphate minerals. It is well known that minerals such as pyromorphite $\left(\mathrm{Pb}_{5}\left(\mathrm{PO}_{4}\right)_{3} \mathrm{Cl}\right)$ are formed at high concentrations of lead(II) and phosphate in combination with high $\mathrm{pH}$. Several authors employing EXAFS (extended X-ray absorption fine structure) spectroscopy or X-ray diffraction techniques have reported formation of pyromorphite-type mineral phases on iron (hydr)oxides (Weesner and Bleam, 1998; Scheckel and Ryan, 2003; Hashimoto et al., 2009). It has been debated, though, to what extent the immobilisation of lead(II) in soil is really due to formation of pyromorphite. In general the conditions in these studies were such ( $\mathrm{pH}>6$ and/or high dissolved lead(II) concentrations) that the formation of pyromorphite-type mineral phases may have been favourable. According to recent studies, it has been suggested that pyromorphite-type minerals may be responsible for as little as $30 \%$ of the immobilisation if the formation is inhibited by complexation with Fe/Al oxides and/or organic matter (Hashimoto et al., 2009, 2011).

It has been known for a long time that copper(II) and lead(II) are bound strongly to iron (hydr)oxides such as ferrihydrite (e.g., Benjamin and Leckie, 1981). Batch experiments in combination with surface complexation models show that lead(II), and maybe also copper(II), are adsorbed more strongly to a minor part of the sorption sites on ferrihydrite (Swedlund and Webster, 2001; Swedlund et al., 2003; Gustafsson et al., 2011). Site heterogeneity has also 
been found in the presence of an oxyanion, sulfate, (Swedlund and Webster, 2001; Swedlund et al., 2003).

X-ray absorption spectroscopy (XAS) has frequently been used to study surface complexes with lead(II) and copper(II). Lead(II) forms inner-sphere edge-sharing bidentate complexes on several iron (hydr)oxides, for example on goethite (Bargar et al., 1997b; Ostergren et al., 2000a), hematite (Bargar et al., 1997b), and ferrihydrite (Scheinost et al., 2001; Trivedi et al., 2003) with an average $\mathrm{Pb}^{\cdots} \mathrm{Fe}$ distance of about $3.3 \AA$. Under some circumstances though, there have been indications also of other complexes. An inner-sphere monodentate complex with a $\mathrm{Pb} \cdots$ Fe distance of $3.89 \AA$ was suggested at low $\mathrm{pH}(<4.5)$ for lead(II) adsorption to ferrihydrite (Trivedi et al., 2003). Ostergren et al (2000a), investigating lead sorption to goethite, interpreted a $\mathrm{Pb} \cdots \mathrm{Fe}$ distance of $3.9 \AA$ as a bidentate cornersharing complex.

Copper(II) forms inner-sphere edge-sharing bidentate complexes on ferrihydrite (Scheinost et al., 2001; Moon and Peacock, 2012), with an average $\mathrm{Cu}^{\cdots}$ Fe distance of about $3.0 \AA$. In contrast, for goethite, hematite and lepidocrocite, EXAFS evidence for corner-sharing bidentate complexes has been obtained, in which the $\mathrm{Cu}^{\cdots}{ }^{\cdots} \mathrm{Fe}$ distance is longer, i.e. between 3.2 and $3.4 \AA$ (Peacock and Sherman, 2004). Parkman et al (1999) suggested that a longer $\mathrm{Cu} \cdots \mathrm{Fe}$ distance of $3.67 \AA$ on lepidocrocite could also be interpreted as a corner-sharing complex.

Xie and Giammar (2007) showed that the addition of phosphate increased lead(II) sorption to goethite. In contrast, Weesner and Bleam (1998) did not observe any significant effect on lead(II) sorption to goethite upon the addition of phosphate. The reasons for the different observations in these two studies are not clear but might be related to differences in experimental setup. Weesner and Bleam (1998) performed batch experiments with $2 \mu \mathrm{M}$ lead(II) and $2 \mu \mathrm{M}$ phosphate $/ \mathrm{m}^{2}$ goethite while Xie and Giammar used recirculating microcolumns containing goethite coated sand, $0.8 \mu \mathrm{M} \mathrm{Pb} / \mathrm{m}^{2}$ goethite and a wide range of 
phosphate concentrations. Interestingly, in spite of the absence of increased sorption in the systems with phosphate, Weesner and Bleam (1998) draw the conclusion that lead(II) adsorbs as an inner-sphere complex and interacts with phosphate at the oxide-solution interface. Xie and Giammar (2007), on the other hand, used a surface complexation model according to which the enhanced lead(II) adsorption in presence of phosphate could be explained mainly by electrostatic interaction. Ternary lead(II)-goethite complexes have been reported to form on goethite with anions such as sulphate, carbonate and chloride (ie. Elzinga et al., 2001; Ostergren et al., 2000a; 2000b; Bargar et al., 1998). These authors found spectroscopic evidence for the formation of monodentate or bidentate corner-sharing lead-ferrihydrite complexes further stabilized by the anion.

Phosphate effects on copper(II) interaction with iron oxy(hydro)xides have been less studied but Nelson (2012) showed that arsenate, a closely related anion, enhanced copper sorption to goethite. Based on surface complexation modeling this was attributed to the formation of two ternary surface complexes. One (dominating) with the components arranged in the order surface-ligand-metal (a type B complex) and one with the components arranged in the order surface-metal-ligand (a type A complex). Few spectroscopic data on the addition of phosphate to $\mathrm{Cu}(\mathrm{II})$ iron (hydr)oxide system exist. A related system studied by Sheals et al. (2003), showed that copper(II) forms ternary complexes with goethite in the presence of phosphomethylglycine (PMG). At low $\mathrm{pH}$ a type $\mathrm{B}$ complex was suggested (components arranged as: surface-PMG-Cu(II)) but at high $\mathrm{pH}$ there were indications of a type A complex (components arranged as: surface-Cu(II)-PMG).

In this study we investigate the effect of phosphate on sorption of copper(II) and lead(II) to ferrihydrite, at low equilibrium copper(II) and lead(II) concentrations typical for mildly contaminated soils (soils containing a few hundred $\mathrm{mg} / \mathrm{kg} \mathrm{dw}$ of copper or lead, based on Swedish classification of contaminated soils (Swedish EPA, 2002)). Ferrihydrite is a poorly 
crystalline iron (hydr)oxide common in nature. Due to its extremely large surface area and reactivity, ferrihydrite is important for metal retention in the environment (Jambor and Dutrizac, 1998). The aim was to identify the surface complexes formed and to derive constants for the surface complexation reactions. To do this a combination of batch experiments, EXAFS spectroscopy and surface complexation modeling with the three-plane CD-MUSIC model was applied.

\section{MATERIALS AND METHODS}

\subsection{Ferrihydrite preparation}

2-line ferrihydrite was prepared using the method of Swedlund and Webster (1999) and Schwertmann and Cornell (2000). A solution containing $36 \mathrm{mM} \mathrm{Fe}\left(\mathrm{NO}_{3}\right)_{3}$ and $12 \mathrm{mM} \mathrm{NaNO}$ was brought to $\mathrm{pH} 8.0$ through drop-wise addition of $4 \mathrm{M} \mathrm{NaOH}$ (prepared just before it was used). The resulting suspension was aged for about $16 \mathrm{~h}$ at $20{ }^{\circ} \mathrm{C}$. Iron (hydr)oxide particles from such a suspension have earlier been examined by Fe K-edge EXAFS spectroscopy (spectrum shown by Gustafsson et al., 2007) and found to be 2-line ferrihydrite. After synthesis the ferrihydrite suspension was back-titrated with $0.1 \mathrm{M} \mathrm{HNO}_{3}$ to $\mathrm{pH} 4.6$ and stirred for about 30 min just before starting the batch experiments to avoid the presence of excessive $\mathrm{CO}_{2}$ in the suspensions.

\subsection{Batch experiments}

Batch experiments producing data for copper(II) and lead(II) adsorption to ferrihydrite as well as copper(II) and lead(II) adsorption to ferrihydrite in presence of phosphate were all prepared and analyzed as described below. The data for lead(II) adsorption to ferrihydrite in absence of phosphate that are discussed has been published in Gustafsson et al. (2011). 
To prepare suspensions for batch experiments an amount of ferrihydrite suspension was first mixed with water and stock solution of $\mathrm{NaNO}_{3}$ to produce a background electrolyte concentration of $0.01 \mathrm{M}$. Then various amounts of acid $\left(\mathrm{HNO}_{3}\right)$ or base $(\mathrm{NaOH}$, prepared the same day) were added to produce a range of $\mathrm{pH}$ values to cover the adsorption edges. Then an aqueous solution of $\mathrm{NaH}_{2} \mathrm{PO}_{4}$ was added directly followed by addition of aqueous solutions of $\mathrm{Pb}\left(\mathrm{NO}_{3}\right)_{2}$ or $\mathrm{Cu}\left(\mathrm{NO}_{3}\right)_{2}$.

The samples were equilibrated in tightly sealed $40 \mathrm{~mL}$ polypropylene centrifuge tubes placed on an end-over-end shaker and shaken gently for $24 \mathrm{~h}$ at room temperature $\left(21^{\circ} \mathrm{C}\right)$. They were then centrifuged for $20 \mathrm{~min}$ at about $3000 \mathrm{~g}$ and filtered using $0.2-\mu \mathrm{m}$ single-use filters (Acrodisc PF, Pall Corporation, Ann Arbor, MI). The $\mathrm{pH}$ was measured on the unfiltered supernatant using a Radiometer combination electrode. Part of the filtered suspension was acidified $\left(1 \% \mathrm{HNO}_{3}\right)$ and analyzed for $\mathrm{Cu}$ and $\mathrm{Pb}$ with inductively coupled plasma mass spectroscopy (ICP-MS) using a Perkin-Elmer ELAN 6100 instrument (PerkinElmer Inc., Waltham, MA, USA). Dissolved phosphate concentrations were analyzed on filtered samples with the acid molybdate method using flow injection analysis (AquatecTecator Autoanalyzer, Foss Analytical, Copenhagen).

Gustafsson et al. (2011) examined possible artifacts because of iron dissolution at low pH and lead(II) adsorption to container walls and to the filters; these effects were found to be very small although a slight contribution was possible at the highest $\mathrm{Pb} / \mathrm{Fe}$ ratio. The adsorption of copper(II) to container walls and filters was investigated within this study and the conclusions were similar. Results from equilibrating $3 \mathrm{mM}$ copper(II) solutions without ferrihydrite show $0.6,1.6$ and $8 \%$ copper(II) adsorption at $\mathrm{pH} 3.9,4.5$ and 5.3, respectively. Therefore no strong contribution from container wall or filter sorption is expected except perhaps at the highest $\mathrm{pH}$ level of the system with the highest $\mathrm{Cu} / \mathrm{Fe}$ ratio (results were not corrected for this effect). The interference of carbonate is also likely to be small. Dissolved 
inorganic carbon was measured in separate batch experiments conducted at $\mathrm{pH} 4$ to 10 with no metals added. Below pH 6.3 inorganic carbon concentration was less than $13 \mu \mathrm{M}$ and at pH 7.3 less than $41 \mu \mathrm{M}$. All suspensions were undersaturated with respect to known lead(II) and copper(II)-carbonate phases (the least soluble being cerrusite, $\mathrm{PbCO}_{3}(\mathrm{~s}), \log K_{\mathrm{s}}=-13.2$ at $\left.25^{\circ} \mathrm{C}\right)$. By use of a surface complexation model based on the carbonate adsorption data of Zachara et al. (1987), we concluded that carbonate might have a very small influence on surface complexation of lead(II) and copper(II) in the highest $\mathrm{pH}$ range of this study, but should not at all affect the results below pH 6.3, the main condition in this study. These results are in accordance with the observations of Villalobos et al. (2001), who concluded that the presence of up to $1 \% \mathrm{CO}_{2}$ did not affect $\mathrm{Pb}^{2+}$ sorption to goethite below $\mathrm{pH}$ 6.5. For the $\mathrm{X}$-ray spectroscopic measurements ferrihydrite was sampled directly from batch experiments conducted immediately before measurements.

\subsection{X-ray absorption spectroscopy}

X-ray spectroscopic measurements of ferrihydrite samples from the batch experiments were performed at the $\mathrm{Cu} \mathrm{K}$ and $\mathrm{Pb} \mathrm{L}_{3}$ edges. The measurements were conducted at the wiggler beam line 4-1 at Stanford Synchrotron Radiation Lightsource (SSRL), Stanford, USA, in February 2011. The beam line operated at $3.0 \mathrm{GeV}$ and with a ring current of $197-200 \mathrm{~mA}$ (top-up mode). The station was equipped with a Si[220] double crystal monochromator. The measurements were performed in fluorescence mode using a 13 element Ge array fluorescence detector. For $\mathrm{Cu}$, a combination of $\mathrm{Ni}$ and $\mathrm{Al}$ filters were used, together with Soller slits, to reduce Fe fluorescence and scattering contributions. For $\mathrm{Pb}, \mathrm{Al}$ and Ge filters were used, with otherwise the same setup as for $\mathrm{Cu}$. The $\mathrm{Si}[220]$ monochromator was detuned $50 \%(\mathrm{Cu})$ or $60 \%(\mathrm{~Pb})$ of maximum intensity to reduce higher-order harmonics. Internal energy calibration was made with a foil of metallic copper or lead assigned to 8.979 and 
$13.035 \mathrm{keV}$, respectively (Thompson et al., 2009). Between 10 and 20 scans were collected per sample. All EXAFS spectra were then treated in the Athena software (version 0.8.061) (Ravel and Newville, 2005). Sample scans were individually studied to identify and discard poor scans. Energy calibration, averaging and background removal were carried out using the procedures described by Kelly et al. (2008). The background was removed using the AUTOBAK algorithm incorporated in Athena, with a $k$-weight of 2 or 3 and with the Rbkg parameter set to 1 for copper(II) and to 1.1 for lead(II). A model of the first shell was used to improve the background for copper(II) spectra, as described by Kelly et al. (2008).

To decide if a certain peak in the Fourier transform originates from a heavy or a light backscatterer, wavelet transform (WT) analyses of the EXAFS spectra can be performed (Funke et al., 2005), and has been implemented in several recent studies (e.g. Karlsson et al, 2008; Loring et al, 2009). In simplified terms, the wavelet transform is a 3-D image that combines the EXAFS-spectra in $k$-space and $r$-space (FT transform) where the back-scattering of the elements appear with high intensity. Depending on the weight of the back-scatterer the maximum intensity appears at different $k$-values. The Morlet wavelet transform incorporated in the Igor Pro script was used (Wavelet2.ipf; Chukalina, 2010). EXAFS spectra $\left(k^{3}-\right.$ weighted) were imported to the script, and a wavelet parameter combination of $\kappa=7$ (copper) or $\kappa=6$ (lead) and $\sigma=1$ was used, with a range of $R+\Delta R$ from 2 to $4 \AA$ (corresponding to interatomic distances of about 2.5 to $4.5 \AA$ ). The $k$-range used was from 2.7 to $9-10.5 \AA^{-1}$ for the copper(II) spectra, and from 2.25 to $8-9 \AA^{-1}$ for the lead(II) spectra (the same $k$-ranges as used in the EXAFS fitting procedure described below).

The Artemis program (Ravel and Newville, 2005) was used for final data treatment of the EXAFS spectra. Theoretical scattering paths were calculated using FEFF (Ankudinov et al., 1998). For copper(II), they were based on the structure of copper(II) hydroxide, $\mathrm{Cu}(\mathrm{OH})_{2}$, (Oswald et al, 1990), cornetite, $\mathrm{Cu}_{3} \mathrm{PO}_{4}(\mathrm{OH})_{3}$, (Eby and Hawthorne, 1989) and libethenite, 
$\mathrm{Cu}_{2} \mathrm{PO}_{4} \mathrm{OH}$, (Heritsch, 1940) with partial Fe-for-Cu substitution, except for the $\mathrm{Cu}-\mathrm{O}$ multiple scattering paths that were calculated directly in FEFF. For lead(II), the scattering paths were based on the structure of red tetragonal lead(II) oxide, PbO, (Leciejewicz, 1961), pattersonite, $\mathrm{PbFe}_{3}\left(\mathrm{PO}_{4}\right)_{2}(\mathrm{OH})_{4}\left[\left(\mathrm{H}_{2} \mathrm{O}\right)_{0.5}(\mathrm{OH})_{0.5}\right]_{2}$, (Kolitsch et al., 2008) with partial Fe-for-P substitution, and lead tetrapolyphosphate (Averbuch-Pouchot and Durif, 1987) with partial Fe-for-Pb substitution. The fitting procedure was performed on the Fourier transform real part between 1 and $4 \AA$ for copper(II), and between 1.1 and $4 \AA$ for lead(II) using a Hanning window (dk value $=1$ ) and optimizing over $k$-weights of 1,2 and 3. Refined models were evaluated not only by means of goodness-of-fit (as evidenced by the $R$ factor in Artemis), but also by qualitative comparison of WT plots of the model spectra with WT plots of the EXAFS spectra.

During the fitting procedure the amplitude reduction factor $\left(S_{0}^{2}\right)$ was set to 0.8 for copper(II) spectra and to 1.0 for lead(II) spectra based on fitting of this parameter for the first coordination shell. For copper(II) samples without phosphate, one $\mathrm{Cu}^{-} \mathrm{O}$ path corresponding to four axial oxygens, three multiple scattering paths $\left(\mathrm{Cu}^{-} \mathrm{O}^{-} \mathrm{O}\right.$ paths at $\left.180^{\circ}\right)$, and one $\mathrm{Cu}^{\cdots} \mathrm{Fe}$ path $\left(\mathrm{Cu}{ }^{\cdots} \mathrm{Fe} 1\right)$ were used. Several other combinations of scattering paths were tested in the fitting procedure before deciding to use these paths, including contributions from two $\mathrm{Cu}^{\cdots} \mathrm{Fe}$ distances and multiple scattering from $\mathrm{Cu}-\mathrm{O}-\mathrm{O}$ paths at $90^{\circ}$ and $\mathrm{Cu}-\mathrm{O}-\mathrm{Fe}$ paths. For lead(II) samples without phosphate, two $\mathrm{Pb}^{-} \mathrm{O}$ paths were used with $\mathrm{Pb}^{-} \mathrm{O} 1$ representing oxygens attached to the ferrihydrite surface and $\mathrm{Pb}^{-} \mathrm{O} 2$ representing neighboring water (or nitrate) molecules. One $\mathrm{Pb}{ }^{\cdots} \mathrm{Fe} 1$ path was added. Other combinations of contributions from heavy back-scatterers and multiple scattering were also tested, including several $\mathrm{Pb}^{\cdots} \mathrm{Fe}$ distances and multiple scattering from $\mathrm{Pb}-\mathrm{O}-\mathrm{Fe}$ paths and $\mathrm{Pb}-\mathrm{O}-\mathrm{O}$ paths. The coordination numbers (CN) of samples without phosphate were set during fitting based on previous findings for adsorption of copper(II) and lead(II) to ferrihydrite (Scheinost et al., 2001; Moon and 
Peacock, 2012; Trivedi et al., 2003). These show that the first coordination shell of the lead(II) complex is dominated by back-scattering from two oxygens, the first coordination shell of the copper(II) complex is dominated by back-scattering from four axial oxygens and that both copper(II) and lead(II) form edge-sharing bidentate complexes to ferrihydrite. $\mathrm{CN}$ of the second oxygen path of $\mathrm{Pb}$ was set to a number that gave Debye-Waller factors $\left(\sigma^{2}\right)$ larger than the first $\mathrm{Pb}-\mathrm{O}$ paths since they have a higher degree of disorder being more loosely bound. The path lengths (R) and Debye-Waller factors were fitted.

To model the corresponding samples with phosphate (i.e. samples with the same metal and ferrihydrite concentrations but with phosphate added) we used a step-wise approach. After initial investigation of the spectra with different combinations of $\mathrm{Cu} \cdots \mathrm{Fe} / \mathrm{Cu} \cdots \mathrm{P}$ and $\mathrm{Pb} \cdots \mathrm{Fe} / \mathrm{Pb} \cdots \mathrm{P}$ paths we concluded that there was most likely a contribution from the same edge-sharing bidentate complex as in the samples without phosphate. Therefore, to investigate the magnitude of the contribution from this edge-sharing complex and to reduce the number of fitting variables, we used some of the parameters obtained for edge-sharing complexes from fitting the samples without phosphate and fixed them when fitting the samples with phosphate. The Debye Waller factors from the $\mathrm{Cu} \cdots \mathrm{Fe} 1 / \mathrm{Pb} \cdots \mathrm{Fe} 1$ paths and the path-lengths and Debye Waller factors of the multiple scattering paths $\left(\mathrm{Cu}^{-} \mathrm{O}^{-} \mathrm{O}\right)$ were therefore fixed and instead the coordination numbers of the $\mathrm{Cu} \cdots \mathrm{Fe} 1 / \mathrm{Pb} \cdots \mathrm{Fe} 1$ paths were fitted. We then tried adding a $\mathrm{Cu} \cdots \mathrm{P} / \mathrm{Pb} \cdots \mathrm{P}$ path and a second, longer, $\mathrm{Cu} \cdots \mathrm{Fe} / \mathrm{Pb} \cdots \mathrm{Fe}$ path $(\mathrm{Cu} \cdots \mathrm{Fe} 2 / \mathrm{Pb} \cdots \mathrm{Fe} 2)$ in the phosphate-containing samples. The coordination numbers of the $\mathrm{Cu} \cdots \mathrm{Fe} 2 / \mathrm{Pb} \cdots \mathrm{Fe} 2$ paths was defined as $1-\mathrm{Cu} \cdots \mathrm{Fe} 1$ and $1-\mathrm{Pb} \cdots \mathrm{Fe} 1$.

\subsection{Surface complexation modeling}

The three plane CD-MUSIC model was used with new surface charging parameters for ferrihydrite (Table 1). In agreement with recent structural analyses of ferrihydrite (Hiemstra 
and van Riemsdijk, 2009; Hiemstra, 2013), we assumed that triply coordinated $\equiv \mathrm{Fe}_{3} \mathrm{O}$ groups accounted for $20 \%$ of the proton charging whereas singly coordinated $\equiv \mathrm{FeOH}$ groups accounted for the remaining $80 \%$. In line with the simplifications of Hiemstra et al. (2009), the role of doubly coordinated $\equiv \mathrm{Fe}_{2} \mathrm{OH}$ groups was not explicitly considered, and the $\mathrm{p} K_{\mathrm{a}}$ of the $\equiv \mathrm{FeOH}$ and of the $\equiv \mathrm{Fe}_{3} \mathrm{O}$ groups was set to the same value (8.1), see Table 2. To be consistent with Hiemstra and van Riemsdijk (2009), the inner-layer and outer-layer capacitances were set to higher values $\left(1.15\right.$ and $0.9 \mathrm{C} \mathrm{m}^{-2}$, respectively) than for goethite, to reflect the spherical morphology of ferrihydrite. The total density of the $\equiv \mathrm{FeOH}$ and $\equiv \mathrm{Fe}_{3} \mathrm{O}$ groups was set to 7.8 sites $\mathrm{nm}^{-2}$ using a molecular weight of ferrihydrite of $89 \mathrm{~g} / \mathrm{mol}$ and a specific surface area of $650 \mathrm{~m}^{2} \mathrm{~g}^{-1}$. This is a slightly larger site density than in the work of Hiemstra and van Riemsdijk (2009; 7.2 sites $\mathrm{nm}^{-2}$ ), but consistent with the larger densities suggested by Hiemstra (2013). The surface charging parameters were found to provide an excellent description to the acid-base titration results of Hsi and Langmuir (1985; c.f. Fig. S1, Electronic Annex), which have been used in the past to calibrate surface charging models for ferrihydrite (Gustafsson et al., 2009; Hiemstra and van Riemsdijk, 2009). The surface complex-forming ions in this work $\left(\mathrm{Pb}^{2+}, \mathrm{Cu}^{2+}, \mathrm{PO}_{4}{ }^{3-}\right)$ were assumed to react exclusively with the $\equiv \mathrm{FeOH}$ groups, as these are generally considered to be the most reactive ones (Hiemstra et al., 2009).

For $\mathrm{PO}_{4}{ }^{3-}$ adsorption, we used a model description assuming bidentate complexes to be dominant, with CD values calculated by Hiemstra and van Riemsdijk (2006) using DFT (density functional theory). As in previous modeling attempts (Sjöstedt et al., 2009), we also included a doubly protonated monodentate species at low $\mathrm{pH}$. Table 2 lists all surface complexation reactions considered.

The surface complexation reactions for copper(II) and lead(II) were constrained from spectroscopic evidence of this study (c.f. Results section). Therefore in the modeled reaction, 
one $\mathrm{Cu}^{2+}$ or $\mathrm{Pb}^{2+}$ ion was reacted with two $\equiv \mathrm{FeOH}$ groups in systems without phosphate (Table 2). The surface complexation constants and CD (charge distribution) values that describe the change in $o$-plane and $b$-plane charge were fitted. The implementation of the CDMUSIC model for $\mathrm{Pb}^{2+}$ adsorption to ferrihydrite considered surface site heterogeneity by dividing the sites into three groups with different affinities for $\mathrm{Pb}^{2+}$ adsorption. A small part of the sites ( $1 \%$ of the total number of sites) were assigned higher affinities. The high-affinity sites were divided into two groups corresponding to 0.9 and $0.1 \%$ of the total number of sites and the latter group was assigned the highest affinity (Gustafsson et al., 2011). This was not necessary to apply in the case of $\mathrm{Cu}^{2+}$ adsorption, which was described well using an equal affinity for all sites (c.f. Results section).

In the model optimization process, surface complexation constants for single-sorbate systems were optimized with FITEQL ver. 4.0 (Herbelin and Westall, 1999), as modified by Gustafsson (2003) to include the CD-MUSIC model and the description of bidentate complexation reactions using mole fractions (this add-in is available from http://www2.lwr.kth.se/forskningsprojekt/mow/fiteql.htm). FITEQL uses the overall variance $V_{Y}$ as a goodness-of-fit parameter, which is defined as the weighted sum-of-squares divided by the number of degrees of freedom. When $\mathrm{CD}$ values were fitted, the procedure was repeated until an optimal set of $\mathrm{CD}$ values (that led to the lowest $V_{\mathrm{Y}}$ values) was found. For optimization of surface complexation constants for lead(II) and copper(II) adsorption several datasets were considered; the data sets of Benjamin and Leckie $\left(1981 ; 1982\right.$; for $\mathrm{Pb}^{2+}$ and $\mathrm{Cu}^{2+}$ ) Swedlund and Webster (2001; for $\left.\mathrm{Cu}^{2+}\right)$, Swedlund et al. (2003; for $\left.\mathrm{Pb}^{2+}\right)$, Gustafsson et al. (2011; for $\mathrm{Pb}^{2+}$ ) and data for $\mathrm{Cu}^{2+}$ adsorption of this study (Table S2, Electronic Annex). Together these data sets represent a wide variation of metal:Fe ratios and ferrihydrite suspension concentrations. For phosphate adsorption we considered six data sets of which five were collected during the course of this study (Table S3, Electronic Annex). Weighted 
average $\log K^{\prime}$ s and $95 \%$ confidence intervals $(95 \mathrm{CI})$ were calculated according to Dzombak and Morel (1990). The latter are heavily dependent on the assumed uncertainty of the data input to FITEQL - a relative error $S_{\text {rel }}=0.05$ for $\left[\mathrm{H}^{+}\right],\left[\mathrm{Pb}^{2+}\right],\left[\mathrm{Cu}^{2+}\right]$ and $\left[\mathrm{PO}_{4}{ }^{3-}\right]$ was applied, and an absolute error $S_{\mathrm{abs}}=1 \%$ of the total concentration of the sorbing ion (see, e.g., Dzombak and Morel, 1990).

For ternary systems, i.e. for ferrihydrite suspensions that contained both metal $\left(\mathrm{Pb}^{2+}\right.$ or $\mathrm{Cu}^{2+}$ ) and phosphate, initially model predictions were made with Visual MINTEQ (Gustafsson, 2012), assuming that any ternary interactions could be explained with electrostatic interactions only (model 1). To assess if this model possibly could explain our results, uncertainties in the model predictions were calculated from the estimated $95 \mathrm{CI}$ for the individual $\log K$ 's by use of a Monte-Carlo method in which 2000 randomly generated values of each $\log K$ were processed in Visual MINTEQ. For the generated output, the $95 \mathrm{CI}$ for the dissolved concentration of ions in each data point were calculated assuming that the dissolved concentrations were log-normally distributed. We then made a model (model 2) that considered ternary complexes that included two $\equiv \mathrm{FeOH}$ groups, one copper(II) or lead(II) ion and one phosphate ion (consistent with our EXAFS interpretations, c.f. Results section). The surface complexation constants and CD values that describe the change in $o$-plane and $b$-plane charge were fitted. Ternary surface complex formation constants (i.e. for $\mathrm{Pb}-\mathrm{PO}_{4}$ or $\mathrm{Cu}-\mathrm{PO}_{4}$ onto ferrihydrite) could not be optimized in a consistent manner by FITEQL because of poor convergence characteristics. Instead the constants and CD values for these reactions were optimized with a trial-and-error procedure by use of Brent's method to minimize the rmse (root-mean square error) in the adsorbed fraction. As a consequence, the uncertainty of these $\log K^{\prime}$ s was not calculated.

Finally, we tested a model (model 3) that did not include any ternary complexes but monodentate ferrihydrite-metal complexes (Fig. 9B and 9F) that were important in phosphate- 
containing systems but not in systems without phosphate were included. Such monodentate complexes would be in accordance with EXAFS results. The model is discussed in detail in the Electronic Annex.

In their model approach, Hiemstra et al. (2009) divided the $\equiv \mathrm{FeOH}$ groups into two subgroups, one that may form edge-sharing bidentate complexes, and another that can form corner-sharing bidentate complexes. While this makes sense from a structural point of view, we decided (after having tested such an approach) to adopt a simplified approach considering only one type of $\equiv \mathrm{FeOH}$ group. The reason was that the results were almost identical, the main difference being that the surface complexation constants were numerically different. The only notable difference in the model fit was observed at the highest surface coverage in one of the lead(II) data sets. Because of the small differences we used the simpler approach, which results in a substantially smaller number of surface species; this makes the model easier to set up and to treat with optimization software such as FITEQL.

\section{RESULTS}

\subsection{Copper(II), lead(II) and phosphate adsorption to ferrihydrite}

Results from the batch experiments of the copper(II)-ferrihydrite and lead(II)-ferrihydrite systems (Fig. 1) indicate that the adsorption affinity of copper(II) on ferrihydrite is independent of the total copper(II) concentration as long as the sorbed copper(II) is far from saturating the ferrihydrite sorption sites. Copper(II)-ferrihydrite systems with $\mathrm{Cu} / \mathrm{Fe}$-ratios of 0.0001, 0.001 and 0.01 follow essentially the same adsorption edge with about $50 \%$ of the copper adsorbed at $\mathrm{pH} 5.0$. However, at a $\mathrm{Cu} / \mathrm{Fe}$ ratio of 0.1 the adsorption edge moves to higher $\mathrm{pH}$ and only $10 \%$ of the copper is adsorbed at $\mathrm{pH}$ 5.0.

By contrast, the adsorption of lead(II) to ferrihydrite has been shown earlier to be highly dependent on the lead(II) concentration (Gustafsson et al, 2011; results reproduced in Fig. 1). 
When a higher $\mathrm{Pb} / \mathrm{Fe}$ ratio is used, a higher $\mathrm{pH}$ is required to adsorb all lead(II). The shape of the sorption edge also changes slightly to a somewhat flatter shape at higher $\mathrm{Pb} / \mathrm{Fe}$ ratio.

Results from sorption of phosphate to ferrihydrite are plotted in Fig 2. Phosphate adsorption ranges from $90-100 \%$ at $\mathrm{pH} 3$ to $40-60 \%$ at $\mathrm{pH} 7$ in the five series performed within this study.

With phosphate added in the batches, the sorption of copper(II) and lead(II) was enhanced in all experimental series (Fig. 3 and Fig. 4). The effect was larger for lead(II) for which the sorption edge was displaced one $\mathrm{pH}$ unit or more at low $\mathrm{pH}$ when phosphate was added. The enhancement was also distinct, but smaller, for copper(II) except at the highest $\mathrm{Cu} / \mathrm{Fe}$ ratio (0.1), where it was very small. As in the single-sorbate systems the sorption of copper(II) was essentially independent of the copper(II) concentration, whereas the sorption of lead(II) increased at lower $\mathrm{Pb} / \mathrm{Fe}$ ratios. In most experimental series the phosphate concentrations were much higher than the metal concentrations and therefore it was not possible to distinguish any effect of copper(II) or lead(II) on phosphate sorption to ferrihydrite. In one series though, with the highest addition of lead(II) compared to phosphate, there was a clear enhancement of phosphate sorption compared to the corresponding system without lead(II) (Fig. 2).

Visual MINTEQ was used to check for possible precipitation of copper(II) and lead(II) phosphate minerals. However, under the conditions used in this study, all systems were found to be magnitudes under-saturated with respect to known copper(II) and lead(II) phosphates (Table S1, Electronic Annex). The highest saturation indexes recorded were -3.38 for $\mathrm{Cu}_{3}\left(\mathrm{PO}_{4}\right)_{2} \times 3 \mathrm{H}_{2} \mathrm{O}(\mathrm{s}),-1.39$ for $\mathrm{PbHPO}_{4}(\mathrm{~s})$, and -2.14 for $\mathrm{Pb}_{5}\left(\mathrm{PO}_{4}\right)_{3} \mathrm{OH}(\mathrm{s})$. Copper(II) and lead(II) (hydr)oxide minerals were also consistently undersaturated according to Visual MINTEQ. 


\subsection{Structure of copper(II) and lead(II) surface complexes}

Eight samples of ferrihydrite from the batch experiments, four with copper(II) and four with lead(II), were analysed with EXAFS spectroscopy to obtain details about the structure on molecular level. The composition of the samples and their $\mathrm{pH}$ values are listed in Table 3 .

\subsubsection{Copper(II) surface complexes}

Wavelet transform (WT) analysis was used to qualitatively assess the second-shell contributions from heavy back-scatterers such as iron as compared to lighter elements such as oxygen, nitrogen and phosphorus. A heavy element would appear with a maximum in the envelope of $k^{3}$-weighted EXAFS function at $k=8-10 \AA^{-1}$ in the WT analysis of copper(II) spectra, whereas lighter elements have maxima at lower energies. The WT analysis of the EXAFS functions revealed an area of back-scattering from a heavier element at $k=8-10 \AA^{-1}$ at about $R+\Delta R=2.5-3.0 \AA$ (Fig 5) in all copper samples. The intensity of back-scattering at this distance was lower in the WT plot of the corresponding samples with phosphate. The area of back-scattering was also stretched out to about $R+\Delta R=3.5 \AA$ which suggests another heavy back-scatterer at a longer distance from the copper(II) atoms. The first heavy backscatterer, present in all samples, could be fit with an iron atom located at $R=3.00-3.05 \AA$ (Table 3). This is in agreement with the edge-sharing bidentate complex identified on ferrihydrite also by Scheinost et al (2001) and Moon and Peacock (2012). For the samples with phosphate, the intensity of the signal from the first heavy back-scatterer was lower also in the EXAFS Fourier transform fitting; the coordination number decreased from 1 to 0.53 for both samples with $\sigma^{2}$ fixed at the value obtained when fitting the samples without phosphate. Inclusion of a second heavy back-scatterer did not significantly improve the model fits, although it could be included at about $3.6 \AA$ for the samples with phosphate. On the other hand the WT plots of this model with two different $\mathrm{Cu}^{\cdots}$ Fe distances (not shown) resembled 
the WT plots for the original spectra much more closely compared to a model with only one short $\mathrm{Cu}^{\cdots} \mathrm{Fe}$ distance. Possibly, the contribution of a second $\mathrm{Cu}^{\cdots} \mathrm{Fe}$ distance to the EXAFS spectra is too small to be clearly visible in the model spectra. There were also areas of enhanced intensity in all samples at lower energies $\left(k=3-4 \AA^{-1}\right)$ and at $R+\Delta R=2.5-3.2 \AA$, which was interpreted as multiple scattering effects (Fig. 5). These could be reproduced fairly well in the WT plots of the model (data not shown).

Fig. 6 shows the $\mathrm{Cu}$ K-edge EXAFS spectra and corresponding Fourier transforms for the analyzed samples. For all samples, the first coordination shell could be fitted well with four oxygen atoms at an average $\mathrm{Cu}^{-} \mathrm{O}$ distance of 1.94-1.95 $\AA$ (Table 2), which is in excellent agreement with the four equatorial oxygen atoms in the Jahn-Teller-distorted $\mathrm{CuO}_{6}$ octahedron (Persson et al., 2002). The Debye-Waller factors $\left(\sigma^{2}\right)$ were reasonable, between 0.003 and $0.007 \AA^{2}$, with somewhat higher $\sigma^{2}$ values for samples with added phosphate, which could indicate a greater degree of distortion of the $\mathrm{CuO}_{6}$ octahedron in these samples. Addition of two axial oxygens into the model slightly improved the fit for some samples but not for all. Others have also experienced that the two axial oxygens of the $\mathrm{CuO}_{6}$ octahedron are not easy to identify in copper(II) sorption EXAFS spectra (Scheinost et al., 2001; Peacock and Sherman, 2004). Multiple scattering (MS) paths for the $180^{\circ} \mathrm{Cu}^{-} \mathrm{O}$ paths were included, with a path degeneracy of $12\left(3 \mathrm{Cu}^{-} \mathrm{O}^{-} \mathrm{O}\right.$ paths with $\left.\mathrm{CN}=4\right)$, and fitted to 3.93 and $3.88 \AA$, which is about twice the equatorial $\mathrm{Cu}^{-} \mathrm{O}$ distance. Any clear contribution from $\mathrm{Cu}^{\cdots} \mathrm{P}$ distances was not identified in any of the samples.

From the batch experiments it is clear that the phosphate ions stabilize the copper(II)ferrihydrite complexes, at least if $\mathrm{pH}$ is not too high (Fig. 3). The (weak) contribution from a longer $\mathrm{Cu}^{\cdots}$ Fe distance suggested by analysis of EXAFS spectra from samples with phosphate is consistent with formation of a ternary complex including copper(II) and phosphate where the copper(II) is attached to the ferrihydrite surface. It could also be consistent with a 
monodentate copper(II)-ferrihydrite complex. Both these alternatives have been evaluated with the CD-MUSIC model (c.f. 3.3 Surface complexation modeling).

A ternary complex would require part of the copper(II) to be bound to phosphate, with a $\mathrm{Cu}^{\cdots} \mathrm{P}$ distance of max $3.5 \AA$ A Such a $\mathrm{Cu}{ }^{\cdots} \mathrm{P}$ distance could not be identified by EXAFS spectroscopy. This can be explained by $\mathrm{P}$ being a light element and not easily identifiable in the second shell at such a distance. Another possibility is that the interaction between copper(II) and phosphate is of an outer-sphere nature, in which case the $\mathrm{Cu}{ }^{\cdots} \mathrm{P}$ distance would be even longer with a wider distance distribution.

\subsubsection{Lead(II) surface complexes}

Wavelet transform analysis (WT) of the EXAFS functions revealed differences between lead(II) samples with and without phosphate (Fig 7). Areas of back-scattering from a heavier element centered at about $k=5-7 \AA^{-1}$ were pronounced at about $R+\Delta R=2.5-3.0 \AA$ in samples without phosphate. In samples with phosphate the back-scattering was comparatively lower at this distance but the intensity was somewhat enhanced also at longer distances, out to about $\mathrm{R}+\Delta R=3.5 \AA$ which suggests that a heavy back-scatterer is present also at a longer distance in these samples. $\mathrm{A} \mathrm{Pb}^{\cdots}{ }^{\cdots} \mathrm{Fe}$ distance of between 3.36 to $3.43 \AA$ was included for all samples but with a lower $\mathrm{CN}$ for the samples with phosphate, in accordance with the lower amplitude of the peaks for the Fourier transforms for these samples (Fig. 8). In samples with phosphate a second $\mathrm{Pb}^{\cdots} \mathrm{Fe}$ at about $4 \AA$ improved the fit significantly. $\mathrm{A} \mathrm{Pb}{ }^{\cdots}$ Fe distance of about $3.35 \AA$ indicates a bidentate edge-sharing complex and is consistent with earlier results for lead(II) sorption on ferrihydrite (Trivedi et al., 2003; Scheinost., et al 2001; Xu et al., 2006). The longer $\mathrm{Pb}^{\cdots} \mathrm{Fe}$ distance that appeared in samples with phosphate is similar to $\mathrm{Pb}^{\cdots} \mathrm{Fe}$ distances of $3.9 \AA$ A earlier identified for lead(II) adsorption to goethite in presence of sulfate (Ostergren et al. 2000a; Elzinga et al. 2001) carbonate (Ostergren et al., 2000b) or chloride (Bargar et al., 1998) and attributed to the formation of ternary surface complexes. A 
similar distance of $\mathrm{Pb}^{\cdots} \mathrm{Fe} 3.89 \AA$ A was also suggested for a binary lead(II)-ferrihydrite system at low pH by Trivedi et al. (2003) and attributed to a monodentate lead(II) complex. (We did not find this longer $\mathrm{Pb}^{\cdots} \mathrm{Fe}$ distance in samples without phosphate, though.)

The first coordination shell could be modeled with two oxygens at $R=2.33-2.38 \AA$ in all samples. The Debye Waller factors were rather high, $\sigma^{2}=0.009$ and 0.013 , which is typical for lead (Bargar et al., 1997a). A second set of four oxygens ( $\mathrm{Pb}-\mathrm{O} 2)$ with a path length between $R=2.56$ and $2.62 \AA$ and $\sigma^{2}$ at about $0.03 \AA^{2}$ improved the fits. These parameters are in agreement with water molecules (and possibly nitrate), bound to the lead(II) ion (Persson et al. 2011). Due to the wide $\mathrm{Pb}-\mathrm{O}$ bond distance distribution, normally in low symmetry configuration giving large Debye-Waller coefficients (Persson et al. 2011), multiple scattering paths were too weak to be distinguished.

The appearance of a longer $\mathrm{Pb}^{\cdots} \mathrm{Fe}$ distance could be explained by formation of a ternary complex with the lead attached to the ferrihydrite surface or by a monodentate complex. Both these possibilities were tested in surface complexation modeling (c.f. below). A ternary complex would require part of the lead(II) to be bound to phosphate with a $\mathrm{Pb}^{\cdots} \mathrm{P}$ distance of $\max 3.9 \AA$ A. However, this distance could not be identified by EXAFS spectroscopy. As for copper(II), this can be explained by $\mathrm{P}$ being a light element and not easily identifiable in the second shell at such a distance and/or that the interaction is of an outer-sphere nature, with an even longer $\mathrm{Pb}^{\cdots} \mathrm{P}$ distance.

\subsection{Surface complexation modeling}

\subsubsection{Surface complexation modeling in single sorbate systems}

Based on the EXAFS results the required copper(II) adsorption reaction in the CD-MUSIC model was defined as a bidentate complex. The best results were obtained when it was assumed that the bound copper(II) was hydrolyzed, i.e. that one of the solution-oriented 
oxygens in the copper(II) coordination sphere had undergone hydrolysis. In the resulting complex, $\equiv(\mathrm{FeOH})_{2} \mathrm{CuOH}$, the $\mathrm{CD}$ values were fitted to the experimental data and were found to be 0.5 for both the $o$-plane and the $b$-plane, which means that the fraction $(f)$ of the $\mathrm{Cu}^{2+}$ charge attributed to the surface was 0.25 , which is considered a realistic result.

As the results from the copper(II) batch experiments did not indicate any surface site heterogeneity, only one type of site (i.e. one surface complexation constant) was used. With this model, a satisfactory fit was obtained for all considered data sets, using the surface complexation constant given in Table 2 (model fits are shown in Fig. 1 and in Fig. S2, Electronic Annex). Much of the remaining discrepancy is probably caused by uncertainties in the experimental data and can be attributed mainly to the difficulty to obtain precise $\mathrm{pH}$ values in the poorly buffered extracts studied. All equations and constants used are listed in Table 2, and further details are given in Table S5 in the Electronic Annex.

For the lead(II) surface complex, the bidentate complex, $\equiv(\mathrm{FeOH})_{2} \mathrm{~Pb}^{+}$, the model provided an excellent description to the data of Gustafsson et al. (2011) and Swedlund et al. (2003), when surface site heterogeneity was considered (Fig. 1 and Fig. S3, Electronic Annex). This was addressed in the model by dividing the sites into three different classes with different affinity corresponding to $99 \%, 0.9 \%$ and $0.1 \%$ of the surface sites. In this complex, lead(II) is not hydrolyzed and displays an unusually large asymmetry $(f=0.6)$, which would create a slight oversaturation of the surface oxygen ligands. Possibly this situation arises due to weak interaction with a third surface group, which at present is not explicitly included in the model (Gustafsson et al., 2011). Our EXAFS results, showing that lead(II) forms an edge-sharing bidentate complex, is in general accordance with this model description. However, EXAFS results are not available for $\mathrm{Pb} / \mathrm{Fe}$ ratios lower than 0.01 due to the large Debye-Waller factors (large bond distance distribution) of low symmetric lead(II) complexes. Therefore, our 
spectroscopic results could not be used to understand the reasons for the considerable surface site heterogeneity as observed for lead(II).

Consideration of site heterogeneity was important also for the description of the data of Benjamin and Leckie (1981; 1982 Table S5, Electronic Annex). However, for the latter data set the lead(II) binding was systematically weaker than for the two other data sets. The reason for this difference is not known; one possibility could be differences in equilibration time. Whatever the reason, we decided not to consider this data set for the calculation of weighted average $\log K$ 's, as the main objective with this exercise was to provide a solid basis for modeling the ternary lead(II) phosphate systems of this study. To provide input for the modeling in the ternary systems, the sorption of phosphate to ferrihydrite was also investigated. The results are summarized in, Fig. 2 and in Table S6, Electronic Annex. These results are consistent with previous ones (Gustafsson, 2003). It should be noted that it could not be entirely excluded that the precipitation of an iron(III) phosphate such as strengite, $\mathrm{FePO}_{4} \times 2 \mathrm{H}_{2} \mathrm{O}(\mathrm{s})$, could influence the results at low $\mathrm{pH}$. The solubility constant of crystalline strengite, as reported by Iuliano et al. (2007), implies that the phosphate-containing systems are supersaturated with respect to strengite at $\mathrm{pH}<5$ (for systems containing $60 \mu \mathrm{M} \mathrm{P}$ ) and at $\mathrm{pH}<6.5$ (for systems containing $600 \mu \mathrm{M} \mathrm{P}$ ). However, results obtained with infrared spectroscopy and X-ray absorption near-edge structure (XANES) spectroscopy for similar systems did not show any evidence for iron(III) phosphate formation on ferrihydrite (Willett et al., 1988; Khare et al., 2005), and we consider it unlikely that significant amounts of a crystalline iron(III) phosphate mineral could have precipitated during the short-term $(24 \mathrm{~h})$ experiments of this study.

\subsubsection{Surface complexation modeling in ternary systems with phosphate}

In a model with only bidentate metal-ferrihydrite complexes (model 1) the enhanced copper(II) and lead(II) sorption in systems with phosphate could not be described 
satisfactorily by electrostatic interactions only, the exception being the system with the lowest $\mathrm{Cu} / \mathrm{Fe}$ ratio (with $\mathrm{Cu}=30 \mu \mathrm{M}, \mathrm{Fe}=0.3 \mathrm{mM}$, for which phosphate addition did not have a large effect on copper(II) sorption). Examples of model predictions, with $95 \% \mathrm{CI}$, are shown in Fig. 3 and Fig. 4 (as dashed lines). Hence in all but one system, the interactions were stronger than those predicted by electrostatic interactions, indicating the presence of additional interactions. In addition, a significant enhancement of phosphate sorption was also observed in the system with the highest $\mathrm{Pb} / \mathrm{Fe}$ ratio (Fig. 2). For this reason ternary complexes were included, resulting in model 2. Good model fits were obtained by including complexes $\equiv(\mathrm{FeO})_{2} \mathrm{HCuPO}_{3} \mathrm{H}^{0}$ and $\equiv(\mathrm{FeO})_{2} \mathrm{HPbPO}_{3} \mathrm{H}^{0}$ (depicted in Figs. $9 \mathrm{C}$ and $\left.9 \mathrm{G}\right)$. Copper(II) and lead(II) are here monodentately coordinated to the ferrihydrite surface, which is in agreement with interpretation of EXAFS data. The phosphate is protonated, coordinated to the copper(II)/lead(II) ion and at the same time interacting with the surface. The CD values were fit to 0.7 for the $o$-plane and to 0.3 for the $b$-plane for both complexes. This means that the surface oxygens remain slightly undersaturated. This model was also able to describe the effect of lead(II) on sorption of phosphate in the system with the highest $\mathrm{Pb} / \mathrm{Fe}$ and $\mathrm{PO}_{4}$ ratio (Fig. 2).

Similar to the case for single-sorbate systems only one type of surface site was used for the ternary copper(II) complex. For the ternary lead(II) complex however, two sites with two different affinities were required. A higher affinity was used for a small number (1\%) of the surface sites. This resulted in the fits depicted in Fig. 3 and Fig. 4 with rmse $=5.1 \%$ for copper(II) and rmse $=2.0 \%$ for lead(II).

It should be noted that corner-sharing complexes with the metal bidentately attached to the ferrihydrite surface and the phosphate attached only to the metal $\left(\equiv(\mathrm{FeOH})_{2} \mathrm{CuPO}_{4} \mathrm{H}_{2}{ }^{0}\right.$ and $\equiv(\mathrm{FeOH})_{2} \mathrm{PbPO}_{4} \mathrm{H}_{2}{ }^{0}$, shown in Fig. 9D and $\left.9 \mathrm{H}\right)$ would also be consistent with the EXAFS results and yield the same result in the CD-MUSIC model. 
It is also possible to describe the results with a model in which a monodentate metalferrihydrite complex (Figs. 9B and 9F) becomes important in phosphate-containing systems (Model 3, Electronic Annex). However, this model was not able to predict phosphate sorption well in the system with the highest $\mathrm{Pb} / \mathrm{Fe}$ ratio.

\section{DISCUSSION}

The EXAFS results of this study show that the coordination chemistry of copper(II) and lead(II) changes in a similar way when phosphate is added to batches with ferrihydrite and copper(II) or lead(II). The amount of $\mathrm{Cu}^{\cdots} \mathrm{Fe} / \mathrm{Pb}{ }^{\cdots} \mathrm{Fe}$ distances indicating edge-sharing complexes diminishes and is partly replaced by a longer distance that suggests a monodentate, or possibly, corner-sharing metal-ferrihydrite complex. These EXAFS results are, on the whole, consistent with earlier studies on binary systems with copper(II) or lead(II) sorption to ferrihydrite (i.e. Scheinost et al., 2001) and with EXAFS studies of ternary $\mathrm{Pb}(\mathrm{II})-\mathrm{SO}_{4}$ systems with goethite (Ostergren et al., 2000b; Elzinga et al., 2001) indicating $\mathrm{Pb} \cdots \mathrm{Fe}$ distances about $3.9 \AA$ in the presence of sulfate. Chloride and carbonate seem to have the same effect on lead(II) coordination to goethite (Bargar et al., 1998; Ostergren et al., 2000a).

Our parameterization of the CD-MUSIC model for sorption in the single sorbate systems with lead(II) and copper(II) coordinating bidentately to ferrihydrite perform very well for our data (Fig 3 and 4) as well as other datasets (Fig S2, S3, Electronic annex). The use of the CDMUSIC model for lead(II) and copper(II) adsorption on ferrihydrite in single-sorbate systems has also been evaluated by Ponthieu et al. (2006) using datasets of Benjamin and Leckie (1981; 1982). However, their model approach was different from ours and the results are therefore difficult to compare. In agreement with the EXAFS results, we only used bidentate complexes in the model, whereas Ponthieu et al. (2006) also used tridentate complexes. Moreover the latter authors assumed all major types of surface groups $\left(\equiv \mathrm{FeOH}, \equiv \mathrm{Fe}_{2} \mathrm{OH}\right.$ and 
$\equiv \mathrm{Fe}_{3} \mathrm{O}$ ) to adsorb metals. As a result Ponthieu et al. (2006) used six complexes each for copper(II) and lead(II) in their model, whereas we only used one for copper(II) and three for lead(II), but with model fits that are comparable in quality.

For both ternary systems with copper(II) and with lead(II) the best modeling results were obtained by introducing a ternary complex involving the metal ion, the phosphate ion and the ferrihydrite surface (model 2). Such a model was able to describe the mutual enhancement of metal and phosphate sorption in the ternary systems. The EXAFS and surface complexation modeling results are consistent with two types of ternary complexes; (i) a ternary surface complex where both metal and phosphate interact monodentately with the ferrihydrite surface (composition $\equiv(\mathrm{FeO})_{2} \mathrm{HMePO}_{3} \mathrm{H}^{0}$, structure in Fig 9C and 9G), and (ii) a corner-sharing ferrihydrite-metal complex in which the phosphate ion is bound to the metal but not to the surface resulting in a type A complex with the composition $\equiv(\mathrm{FeOH})_{2}-\mathrm{Me}-\mathrm{H}_{2} \mathrm{PO}_{4}(\mathrm{Fig} 9 \mathrm{~B}$ and 9H).

If the metal-ferrihydrite distances of $4.0 \AA$ for lead(II) and $3.6 \AA$ for copper(II) are interpreted as evidence for monodentate coordination of copper(II) and lead(II) to the surface (in agreement with option (i) above), EXAFS results would also be consistent with a ternary type A complex with the composition $\equiv(\mathrm{FeOH}) \mathrm{MePO}_{4}$. However, this complex, including only one surface group, was considered less likely as such a model yields a poorer fit (not shown) and too large CD values for the $o$-plane.

Concerning option (ii), previous authors have attributed a $3.9 \AA \mathrm{Pb} \cdots \mathrm{Fe}$ distance also to the formation of corner-sharing complexes. In particular Ostergren et al. (2000b) interpreted EXAFS results for a ternary goethite-lead(II)-sulfate system as corner-sharing $\equiv(\mathrm{FeOH})_{2}$ $\mathrm{Pb}$ (II)-SO $\mathrm{SO}_{4}$ complexes where the sulfate ion interacts only with lead(II) and not with the surface. We do not rule out this interpretation on the basis of our EXAFS results, as the 
$\mathrm{Pb}^{\cdots} \mathrm{F}$ Fe distance at $4.0 \AA$ may be interpreted as a corner-sharing complex. Although we have used $\mathrm{CN}=1$ for the $\mathrm{Pb}{ }^{\cdots} \mathrm{Fe}$ distance in the EXAFS model in agreement with option (i) (Table 3), very similar fits can be obtained also with $\mathrm{CN}=2$, which is expected for a ternary cornersharing complex. The same is true for a $\mathrm{Cu}^{\cdots}{ }^{\cdots} \mathrm{Fe}$ distance of $3.6 \AA$. To our knowledge there are no EXAFS studies on systems with copper(II), iron (hydr)oxide and inorganic ligands, but a $\mathrm{Cu}^{\cdots} \mathrm{F}$ Fe distance of $3.67 \AA$ for copper(II) sorption to lepidocrocite was interpreted as a cornersharing complex by Parkman et al. (1999). To find out the surface structure more precisely additional EXAFS studies and/or ATR-FTIR (Attentuated Total Reflectance Fourier Transform Infrared Spectroscopy) studies are needed. EXAFS analyses could be made for ternary systems in which a heavier analogue to $\mathrm{P}$ (preferably As) is used. Thus the changes in the coordination of the ligand could also be investigated.

As the $4.0 \AA \mathrm{Pb}^{\cdots} \mathrm{Fe}$ and the $3.6 \AA \mathrm{Cu}^{\cdots}{ }^{\cdots} \mathrm{Fe}$ distances may indicate monodentate coordination with the ferrihydrite surface and we do not distinguish any $\mathrm{Pb}^{\cdots} \mathrm{P}$ or $\mathrm{Cu}^{\cdots} \mathrm{P}$ distances, the EXAFS results are also consistent with the formation of monodentate $\mathrm{FeOHCu}^{+1.5}$ or $\mathrm{FeOHPb}^{+1.5}$ complexes (Fig 9B and 9F). Model 3, in which these complexes were included, but not any ternary complexes, was able to explain the enhanced sorption of copper(II) and lead(II) quite well (for details, see Electronic Annex). Although this possibility cannot be discounted, we consider this alternative less likely, mostly because of the relatively poor prediction of phosphate in the ternary system at the highest $\mathrm{Pb} / \mathrm{Fe}$ ratio. Moreover, because the equilibrium constant of the monodentate complex could not be determined in single-sorbate systems, and since no presence of a monodentate complex could be detected with EXAFS spectroscopy in single-sorbate systems, there is no experimental support neither for the existence of such a complex nor for the value of its equilibrium constant.

In all our sorption experiments the $\mathrm{pH}$ value is a crucial parameter. Whereas the sorption of copper(II) and lead(II) increases at higher $\mathrm{pH}$, the sorption of phosphate is higher at low $\mathrm{pH}$. 
In Fig. 10, a model simulation of the effect of phosphate on the partitioning between the proposed surface complexes is shown. The simulation was made in Visual MINTEQ using the surface complexation constants of Table 2 and by fixing the total dissolved phosphate concentrations. According to the simulation, the ternary surface complexes are important under acidic conditions, below about $\mathrm{pH}$ 6, and they are more important for lead(II) than for copper(II). For copper(II), very high dissolved phosphate concentrations are needed for any significant amounts of ternary complexes to be formed at $\mathrm{pH}$ above 6 . This reflects the much larger effect on lead(II) sorption upon addition of phosphate. Similarly, the small difference in copper(II) sorption in systems with and without phosphate at the highest $\mathrm{Cu} / \mathrm{Fe}$ ratio (Fig. 3) can partly be attributed to the high $\mathrm{pH}$ at the adsorption edge.

The results from this study show that phosphate may greatly enhance the adsorption of lead(II) and copper(II) at low $\mathrm{pH}$ and that this is best explained by the formation of ternary surface complexes. Geochemical models used for simulating trace element behavior in acidic environments need to account for this type of reaction to properly describe partitioning of metals between solution and the solid phase.

Acknowledgements: This research was funded by the Geological Survey of Sweden (SGU). Portions of this research were carried out at the Stanford Synchrotron Radiation Lightsource, a Directorate of SLAC National Accelerator Laboratory and an Office of Science User Facility operated for the U.S. Department of Energy Office of Science by Stanford University. The SSRL Structural Molecular Biology Program is supported by the DOE Office of Biological and Environmental Research, and by the National Institutes of Health, National Center for Research Resources, Biomedical Technology Program (P41RR001209). Abubaker Edkymish, Maja Larsson and Lena Ek are thanked for parts of the laboratory work. 


\section{RERERENCES}

Ankudinov, A.L., Ravel, B., Rehr, J.J. and Conradson, S.D. (1998) Real-space multiplescattering calculation and interpretation of X-ray absorption near-edge structure. Phys. Rev. $B$ 58, 7565-7576.

Averbuch-Pouchot, M. and Durif, A. (1987) Structure of lead tetrapolyphosphate. Acta Cryst. C 43, 631-632.

Bargar J. R., Brown G. E., Jr. and Parks G. A. (1997a) Surface complexation of Pb(II) at oxide-water interfaces: I. XAFS and bond-valence determination of mononuclear and polynuclear $\mathrm{Pb}(\mathrm{II})$ sorption products on aluminum oxides. Geochim. Cosmochim. Acta 61, 2617-2638.

Bargar, J.R., Brown, G.E. and Parks, G.A. (1997b) Surface complexation of Pb(II) at oxidewater interfaces: II. XAFS and bond-valence determination of mononuclear $\mathrm{Pb}(\mathrm{II})$ sorption products and surface functional groups on iron oxides. Geochim. Cosmochim. Acta 61, 2639-2652.

Bargar, J.R., Brown, G.E. and Parks, G.A. (1998) Surface complexation of Pb(II) at oxidewater interfaces: III. XAFS determination of $\mathrm{Pb}(\mathrm{II})$ and $\mathrm{Pb}(\mathrm{II})$-chloro adsorption complexes on goethite and alumina. Geochim. Cosmochim. Acta 62, 193-207.

Benjamin, M.M. and Leckie, J.O. (1981) Mutliple-site adsorption of $\mathrm{Cd}, \mathrm{Cu}, \mathrm{Zn}$ and $\mathrm{Pb}$ on amorphous iron oxyhydroxide. J. Colloid Interface Sci. 79, 209-221.

Benjamin, M.M. and Leckie, J.O. (1982) Effects of complexation by $\mathrm{Cl}, \mathrm{SO}_{4}$, and $\mathrm{S}_{2} \mathrm{O}_{3}$ on adsorption behavior of Cd on oxide surfaces. Environ. Sci. Technol. 16, 162-170.

Cao, X., Ma, L.Q., Chen, M., Singh, S.P. and Harris, W.G. (2002) Impacts of phosphate amendments on lead biogeochemistry at a contaminated site. Environ. Sci. Technol. 36, $5296-5304$ 
Chukalina, M. (2010) Wavelet2.ipf, a procedure for calculating the Wavelet transform in IGOR Pro. Downloaded from website in November 2011: http://www.esrf.eu/UsersAndScience/Experiments/CRG/BM20/Software/Wavelets/IGOR

Eby, R. K. and Hawthorne, F. C. (1989) Cornetite: modulated densely-packed Cu2+ oxysalt. Mineralogy and Petrology 40, 127-136

Elzinga, E.J., Peak, D. and Sparks, D.L. (2001) Spectroscopic studies of Pb(II)-sulfate interactions at the goethite-water interface. Geochim. Cosmochim. Acta 65, 2219-2230.

Funke, H., Scheinost, A.C. and Chukalina, M. (2005) Wavelet analysis of extended X-ray absorption fine structure data. Phys. Rev. B 71, 094110.

Gustafsson, J.P. (2003) Modelling molybdate and tungstate adsorption to ferrihydrite. Chem. Geol. 200, 105-115.

Gustafsson J.P. (2012) Visual MINTEQ 3.0. Available at http://www2.lwr.kth.se/english/OurSoftWare/Vminteq/index.html.

Gustafsson, J.P., Persson, I., Kleja, D.B. and van Schaik, J.W.J. (2007) Binding of iron(III) to organic soils: EXAFS spectroscopy and chemical equilibrium modeling. Environ. Sci. Technol. 41, 1232-1237.

Gustafsson, J.P., Dässman, E. and Bäckström, M. (2009) Towards a consistent geochemical model for prediction of uranium(VI) removal from groundwater by ferrihydrite. Appl. Geochem. 24, 454-462.

Gustafsson, J.P., Tiberg, C., Edkymish, A. and Kleja, D.B. (2011) Modelling lead(II) sorption to ferrihydrite and soil organic matter. Environ. Chem. 8, 485-492.

Hashimoto, Y., Takaoka, M., Oshita, K. and Tanida, H. (2009) Incomplete transformations of $\mathrm{Pb}$ to pyromorphite by phosphate-induced immobilization investigated by X-ray absorption fine structure (XAFS) spectroscopy. Chemosphere 76, 616-622. 
Hashimoto, Y., Takaoka, M.and Shiota, K. (2011) Enhanced transformation of lead speciation in rhizosphere soils using phosphate amendments and phytostabilization: an X-ray absorption fine structure investigation. J. Environ. Qual. 40, 696-703.

Herbelin, A.L. and Westall, J.C. (1999) FITEQL 4.0: A Computer Program for Determination of Chemical Equilibrium Constants from Experimental Data. Report 99-0a. Department of Chemistry, Oregon State University, Corvallis.

Heritsch, H. (1940) Die Struktur des Libethenites Cu2(OH)[PO4]. Z. Kristallogr. 102, 1-12.

Hiemstra, T. (2013) Surface and mineral structure of ferrihydrite. Geochim. Cosmochim. Acta 105, 316-325.

Hiemstra, T. and van Riemsdijk, W.H. (1996) A surface structural approach to ion adsorption: The charge distribution (CD) model. J. Colloid Interface Sci. 179, 488-508.

Hiemstra, T. and van Riemsdijk, W.H. (2006) On the relationship between charge distribution, surface hydration, and the structure of the interface of metal hydroxides. $J$. Colloid Interface Sci. 301, 1-18.

Hiemstra, T. and van Riemsdijk, W.H. (2009) A surface structural model for ferrihydrite I: Sites related to primary charge, molar mass, and mass density. Geochim. Cosmochim. Acta 73, 4423-4436.

Hiemstra, T., van Riemsdijk, W.H., Rossberg, A. and Ulrich, K.U. (2009) A surface structural model for ferrihydrite II: Adsorption of uranyl and carbonate. Geochim. Cosmochim. Acta 73, 4437-4451.

Hsi, C.D. and Langmuir, D. (1985) Adsorption of uranyl onto ferric oxyhydroxides: application of the surface complexation site-binding model. Geochim. Cosmochim. Acta 49, 1931-1941.

Iuliano, M., Ciavatta, L. and De Tommaso, G. (2007) On the solubility constant of strengite. Soil Sci. Soc. Am. J. 71, 1137-1140. 
Jambor, J.L. and Dutrizac, J.E. (1998) Occurrence and consitution of natural and synthetic ferrihydrite, a widespread iron oxyhydroxide. Chem. Rev. 98, 2549-2585.

Kelly, S., Hesterberg, D. and Ravel, B. (2008) Analysis of soils and minerals using X-ray absorption spectroscopy. In: Methods of soil analysis. Part 5. Mineralogical methods. (eds. A.L. Ulery and L.R. Drees). SSSA Book Series Ser. 5, SSSA, Madison, WI.

Khare, N., Hesterberg, D. and Martin, J.D. (2005) XANES investigation of phosphate sorption in single and binary systems of iron and aluminium oxide minerals. Environ. Sci. Technol. 39, 2152-2160.

Kolitsch, U., Bernhardt H-J, Krause, W. and Blass, G. (2008) Pattersonite, a new supergene phosphate mineral: description and crystal structure. Eur. J. Mineral. 20, 281-288.

Leciejewicz, J. (1961) On the crystal structure of tetragonal (red) PbO. Acta Crystallogr. 14, 1304.

Ma, L. Q., Santos, J., Cao, X., Saha, U. and Harris, W. (2008) Field application of phosphate rock for remediation of metal-contaminated soils, Publication No. 01-148-226, (Editor Karen J. Stewart), Florida state institute of phosphate research, Florida, USA.

Moon, E.M., Peacock, C.L. (2012). Adsorption of Cu(II) to ferrihydrite-bacteria composites: Importance of the carboxyl group for $\mathrm{Cu}$ mobility in natural environments, Geochim. Cosmochim. Acta, 2012, DOI:10.1016/j.gca.2012.06.012

Nelson, H. (2012) Modelling precipitation and surface complexation reactions in systems with goethite, $\mathrm{Cu}(\mathrm{II})$ and oxyanions containing $\mathrm{As}(\mathrm{V})$ or $\mathrm{P}(\mathrm{V})$. PhD thesis, Department of Chemistry, Umeå University, Umeå, Sweden. Available at: http://www.divaportal.org/smash/record.jsf?searchId=1\&pid=diva2:508296\&rvn=4

Ostergren, J.D., Trainor, T.P., Bargar, J.R., Brown, G.E. and Parks, G.A. (2000a) Inorganic ligand effects on $\mathrm{Pb}(\mathrm{II})$ sorption to goethite $(\alpha-\mathrm{FeOOH})$ - I. Carbonate. J. Colloid Interface Sci. 225, 466-482. 
Ostergren, J.D., Brown, G.E., Parks, G.A. and Persson, P. (2000b) Inorganic ligand effects on $\mathrm{Pb}(\mathrm{II})$ sorption to goethite $(\alpha-\mathrm{FeOOH})$ - II. Sulfate. J. Colloid Interface Sci. 225, $483-$ 493.

Oswald, H. R., Reller, A., Schmalle, H. W., Dubler, E., (1990) Structure of copper(II) hydroxide, $\mathrm{Cu}(\mathrm{OH})_{2}$, Acta Cryst. C46, 2279-2284.

Parkman, R.H., Charnock, J.M., Bryan, N.D., Livens, F.R. and Vaughan, D.J. (1999) Reactions of copper and cadmium ions in aqueous solution with goethite, lepidocrocite, mackinawite and pyrite. Am. Mineral. 84, 407-419.

Peacock, C.L. and Sherman, D.M. (2004) Copper(II) sorption on goethite, hematite and lepidocrocite: a surface complexation model based on ab initio molecular geometries and EXAFS spectroscopy. Geochim. Cosmochim. Acta 68, 2623-2637.

Persson, I., Persson, P., Sandström, M. and Ullström, A.S. (2002) Structure of Jahn-Teller distorted solvated copper(II) ions in solution, and in solids with apparently regular octahedral coordination geometry. J. Chem. Soc. Dalton Trans. 2002, 1256-1265.

Persson, I., Lyczko, K., Lundberg, D., Eriksson, L., Placzek, A. (2011) Coordination chemistry study of hydrated and solvated lead (II) ions in solution and solid state. Inorg. Chem. 50 1058-1072.

Ponthieu, M., Juillot, F., Hiemstra, T., van Riemsdijk, W.H. and Benedetti, M.F. (2006) Metal ion binding to iron oxides. Geochim. Cosmochim. Acta 70, 2679-2708.

Ravel, B. and Newville, M. (2005). Athena Artemis Haephestus: Data analysis for X-ray absorption spectroscopy using IFEFFIT. J. Synchrotron Rad. 12, 537-541.

Scheckel, K.G. and Ryan, J.A. (2003) In vitro formation of pyromorphite via reaction of $\mathrm{Pb}$ sources with soft-drink phosphoric acid. Sci. Total Environ. 302, 253-265.

Scheinost, A.C., Abend, S., Pandya, K.I. and Sparks, D.L. (2001) Kinetic controls on Cu and Pb sorption by ferrihydrite. Environ. Sci. Technol. 35, 1090-1096. 
Schwertmann, U. and Cornell, R.M. (2000) Iron oxides in the laboratory: preparation and characterization. Wiley, Weinheim.

Sheals, J., Granström, M., Sjöberg, S. and Persson, P. (2003) Coadsorption of Cu(II) and glyphosate at the water-goethite $(\alpha-\mathrm{FeOOH})$ interface: molecular structures from FTIR and EXAFS measurements. J. Colloid Interface Sci. 262, 38-47.

Sjöstedt, C., Wällstedt, T., Gustafsson, J.P. and Borg, H. (2009) Speciation of aluminium, arsenic and molybdenum in excessively limed lakes. Sci. Total Environ. 407, 5119-5127.

Swedlund, P.J. and Webster, J.G. (1999) Adsorption and polymerisation of silicic acid on ferrihydrite, and its effect on arsenic adsorption. Water Res. 33, 3413-3422.

Swedlund, P.J. and Webster, J.G. (2001) Cu and Zn ternary surface complex formation with $\mathrm{SO}_{4}$ on ferrihydrite and schwertmannite. Appl Geochem. 16, 503-511

Swedlund, P.J. and Webster, J.G and Miskelly, G.M.(2003) The effect of $\mathrm{SO}_{4}$ on the ferrihydrite adsorption of $\mathrm{Co}, \mathrm{Pb}$ and $\mathrm{Cd}$ : ternary complexes and site heterogeneity Appl. Geochem. 18, 1671-1689.

Swedish environmental protection agency (2002), Metodes for inventories of contaminated sites, Report 5053, $1^{\text {st }}$ edition, Fätht and Hässler, Värnamo. Available at: http://www.naturvardsverket.se/Documents/publikationer/620-5053-2.pdf

Thompson, A., Attwood, D., Gullikson, E., Howells, M., Kim, K.-J., Kirz, J., Kortright, J., Lindau, I., Pianetta, P., Robinson, A., Scofield, J., Underwood, J., Williams, G. and Winck, H. (2009) X-ray Data Booklet. Lawrence Berkeley National Laboratory, University of California, Berkeley, California.

Trivedi, P., Dyer, J.A. and Sparks, D.L. (2003) Lead sorption onto ferrihydrite. 1. A macroscopic and spectroscopic assessment. Environ. Sci. Technol. 37, 908-914. 
Weesner, F.J. and Bleam, W.F. (1998) Binding characteristics of $\mathrm{Pb}^{2+}$ on anion-modified and pristine hydrous oxide surfaces studied by electrophoretic mobility and X-ray absorption spectroscopy. J. Colloid Interface Sci. 205, 380-389.

Villalobos, M., Trotz, N.A. and Leckie, J.O. (2001) Surface complexation modeling of carbonate effects on the adsorption of $\mathrm{Cr}(\mathrm{VI}), \mathrm{Pb}(\mathrm{II})$, and $\mathrm{U}(\mathrm{VI})$ on goethite. Environ. Sci. Technol. 35, 3849-3856.

Willett, I.R., Chartres, C.J. and Nguyen, T.T. (1988) Migration of phosphate into aggregated particles of ferrihydrite. J. Soil Sci. 39, 275-282.

Xie, L. and Giammar, D.E. (2007) Influence of phosphate on adsorption and surface precipitation of lead on iron oxide surfaces. In Adsorption of Metals by Geomedia II: Variables, mechanisms, and model applications (eds. M.O. Barnett and D.O. Kent), pp. 349-373. Elsevier, Amsterdam, Netherlands.

Xu, Y., Boonfueng, T., Axe, L., Maeng, S. and Tyson, T. (2006) Surface complexation of $\mathrm{Pb}(\mathrm{II})$ on amorphous iron oxide and manganese oxide: Spectroscopic and time studies. $J$. Colloid Interface Sci. 299, 28-40.

Zachara, J.M., Girvin, D.C., Schmidt, R.L. and Resch, C.T. (1987) Chromate adsorption onto amorphous iron oxyhydroxide in the presence of major groundwater ions. Environ, Sci. Technol. 21, 589-594. 
Table 1

Model parameters for surface charging of ferrihydrite

\begin{tabular}{|c|c|c|c|}
\hline & Gustafsson et al. 2009 & Hiemstra et al. 2009a & This study \\
\hline$A / \mathrm{m}^{2} \mathrm{~g}^{-1}$ & 750 & 650 & 650 \\
\hline$N_{\mathrm{s}, \text { all }} /$ sites $\mathrm{nm}^{-2}$ & 6.3 & 7.2 & 7.8 \\
\hline$N_{\mathrm{s}, \mathrm{FeOH}} /$ sites $\mathrm{nm}^{-2}$ & 6.3 & 6.0 & 6.25 \\
\hline$N_{\mathrm{s}, \mathrm{Fe} 3 \mathrm{O}} /$ sites $\mathrm{nm}^{-2}$ & 0 & 1.2 & 1.55 \\
\hline$C_{1} / \mathrm{F} \mathrm{m}^{-2}$ & 1 & 1.15 & 1.15 \\
\hline$C_{2} / \mathrm{F} \mathrm{m}^{-2}$ & 0.74 & 0.9 & 0.9 \\
\hline
\end{tabular}

$A$ is the specific surface area; $N_{\mathrm{s}}$ is the site density; $C_{1}$ and $C_{2}$ are the inner-layer and outerlayer capacitances, respectively. 


\section{Table 2}

Surface complexation reactions and constants used in the CD-MUSIC model for ferrihydrite.

\begin{tabular}{|c|c|c|c|}
\hline Reaction & $\left(\Delta z_{0}, \Delta z_{1}, \Delta z_{2}\right)^{\mathrm{a}}$ & $\log K^{b}$ & Data source(s) \\
\hline $\mathrm{FeOH}^{1 / 2-}+\mathrm{H}^{+} \leftrightarrow \mathrm{FeOH}_{2}^{1 / 2+}$ & $(1,0,0)$ & 8.1 & Dzombak \& Morel (1990) \\
\hline $\mathrm{Fe}_{3} \mathrm{O}^{1 / 2-}+\mathrm{H}^{+} \leftrightarrow \mathrm{Fe}_{3} \mathrm{OH}^{1 / 2+}$ & $(1,0,0)$ & 8.1 & Assumed the same as above \\
\hline $\mathrm{FeOH}^{1 / 2-}+\mathrm{Na}^{+} \leftrightarrow \mathrm{FeOHNa}^{1 / 2+}$ & $(0,1,0)$ & -0.6 & $\begin{array}{l}\text { Hiemstra \& van Riemsdijk } \\
\qquad(2006)\end{array}$ \\
\hline $\mathrm{Fe}_{3} \mathrm{O}^{1 / 2-}+\mathrm{Na}^{+} \leftrightarrow \mathrm{Fe}_{3} \mathrm{ONa}^{1 / 2+}$ & $(0,1,0)$ & -0.6 & $"$ \\
\hline $\mathrm{FeOH}^{1 / 2-}+\mathrm{H}^{+}+\mathrm{NO}_{3}^{-} \leftrightarrow \mathrm{FeOH}_{2} \mathrm{NO}_{3}^{1 / 2-}$ & $(1,-1,0)$ & 7.42 & $"$ \\
\hline $\mathrm{Fe}_{3} \mathrm{O}^{1 / 2-}+\mathrm{H}^{+}+\mathrm{NO}_{3}^{-} \leftrightarrow \mathrm{Fe}_{3} \mathrm{OHNO}_{3}^{1 / 2-}$ & $(1,-1,0)$ & 7.42 & $"$ \\
\hline $2 \mathrm{FeOH}^{1 / 2-}+2 \mathrm{H}^{+}+\mathrm{PO}_{4}^{3-} \leftrightarrow \mathrm{Fe}_{2} \mathrm{O}_{2} \mathrm{PO}_{2}^{2-}+2 \mathrm{H}_{2} \mathrm{O}$ & $(0.46,-1.46,0)$ & 27.59 & This study $^{\mathrm{c}}$ \\
\hline $2 \mathrm{FeOH}^{1 / 2-}+3 \mathrm{H}^{+}+\mathrm{PO}_{4}^{3-} \leftrightarrow \mathrm{Fe}_{2} \mathrm{O}_{2} \mathrm{POOH}^{-}+2 \mathrm{H}_{2} \mathrm{O}$ & $(0.63,-0.63,0)$ & 32.89 & ” \\
\hline $\mathrm{FeOH}^{1 / 2-}+3 \mathrm{H}^{+}+\mathrm{PO}_{4}^{3-} \leftrightarrow \mathrm{FeOPO}_{3} \mathrm{H}_{2}^{1 / 2-}+\mathrm{H}_{2} \mathrm{O}$ & $(0.5,-0.5,0)$ & 30.23 & , \\
\hline \multirow[t]{3}{*}{$2 \mathrm{FeOH}^{1 / 2-}+\mathrm{Pb}^{2+} \leftrightarrow(\mathrm{FeOH})_{2} \mathrm{~Pb}^{+}$} & $(1.2,0.8,0)$ & $9.58(99 \%)$ & ” \\
\hline & & $12.25(0.9 \%)$ & , \\
\hline & & $14.24(0.1 \%)$ & , \\
\hline $2 \mathrm{FeOH}^{1 / 2-}+\mathrm{Cu}^{2+}+\mathrm{H}_{2} \mathrm{O} \leftrightarrow(\mathrm{FeOH})_{2} \mathrm{CuOH}+\mathrm{H}^{+}$ & $(0.5,0.5,0)$ & 0.97 & " \\
\hline \multirow[t]{2}{*}{$2 \mathrm{FeOH}^{1 / 2-}+2 \mathrm{H}^{+}+\mathrm{Pb}^{2+}+\mathrm{PO}_{4}^{3-} \leftrightarrow(\mathrm{FeO})_{2} \mathrm{HPbPO}_{3} \mathrm{H}^{0}+\mathrm{H}_{2} \mathrm{O}$} & $(0.7,0.3,0)$ & $33.64(99 \%)$ & , \\
\hline & & $37.20(1 \%)$ & , \\
\hline $2 \mathrm{FeOH}^{1 / 2-}+2 \mathrm{H}^{+}+\mathrm{Cu}^{2+}+\mathrm{PO}_{4}{ }^{3-} \leftrightarrow(\mathrm{FeO})_{2} \mathrm{HCuPO}_{3} \mathrm{H}^{0}+\mathrm{H}_{2} \mathrm{O}$ & $(0.7,0.3,0)$ & 31.71 & " \\
\hline
\end{tabular}

${ }^{\text {a }}$ The change of charge in the $o-, b$ - and $d$-planes respectively.

${ }^{\mathrm{b}}$ Two or three numbers indicate binding to sites with different affinity, the percentages of which are within brackets (c.f. text).

${ }^{\mathrm{c}}$ See the text and the Electronic Annex for details 
Table 3. Summary of copper K-edge and lead L3-edge EXAFS shell fit results, uncertainties of fitted parameters within brackets ${ }^{\mathrm{a}}$.

\begin{tabular}{|c|c|c|c|c|c|c|c|}
\hline Sample & Path & $\mathrm{CN}$ & $R(\AA)$ & $\sigma^{2}\left(\AA^{2}\right)$ & $\Delta \mathrm{E}(\mathrm{eV})$ & $\mathrm{S}_{0}{ }^{2}$ & R-factor (\%) \\
\hline Cu 14 pH=5.00 & $\mathrm{Cu}-\mathrm{O}$ & 4 & $1.95(0.02)$ & $0.003(0.001)$ & $-0.6(2.2)$ & 0.8 & 1.2 \\
\hline $30 \mu \mathrm{M} \mathrm{Cu}$ & $\mathrm{Cu} \cdots \mathrm{Fe} 1$ & 1 & $3.05(0.05)$ & $0.006(0.007)$ & & & \\
\hline $3 \mathrm{mM} \mathrm{Fe}$ & Cu-O-O & 12 & $3.93(0.09)$ & $0.005(0.016)$ & & & \\
\hline Cu 16 pH=5.40 & $\mathrm{Cu}-\mathrm{O}$ & 4 & $1.95(0.01)$ & $0.004(0.001)$ & $0.4(1.1)$ & 0.8 & 0.5 \\
\hline $30 \mu \mathrm{M} \mathrm{Cu}$ & $\mathrm{Cu} \cdots \mathrm{Fe} 1$ & $0.53(0.34)$ & $3.03(0.04)$ & 0.006 & & & \\
\hline $3 \mathrm{mM} \mathrm{Fe}$ & Cu-O-O & 12 & 3.93 & 0.005 & & & \\
\hline \multicolumn{8}{|l|}{$600 \mu \mathrm{M} P$} \\
\hline Cu 17 pH=5.85 & $\mathrm{Cu}-\mathrm{O}$ & 4 & $1.94(0.01)$ & $0.005(0.000)$ & $-1.0(0.6)$ & 0.8 & 0.2 \\
\hline $30 \mu \mathrm{M} \mathrm{Cu}$ & $\mathrm{Cu} \cdots \mathrm{Fe} 1$ & 1 & $3.02(0.02)$ & $0.007(0.002)$ & & & \\
\hline $0.3 \mathrm{mM} \mathrm{Fe}$ & Cu-O-O & 12 & $3.88(0.00)$ & $0.005(0.003)$ & & & \\
\hline Cu 18 pH=6.58 & $\mathrm{Cu}-\mathrm{O}$ & 4 & $1.95(0.01)$ & $0.007(0.001)$ & $-0.6(0.8)$ & 0.8 & 0.4 \\
\hline $30 \mu \mathrm{M} \mathrm{Cu}$ & $\mathrm{Cu} \cdots \mathrm{Fe} 1$ & $0.53(0.24)$ & $3.00(0.03)$ & 0.007 & & & \\
\hline $0.3 \mathrm{mM} \mathrm{Fe}$ & Cu-O-O & 12 & 3.88 & 0.005 & & & \\
\hline $60 \mu \mathrm{M} P$ & & & & & & & \\
\hline
\end{tabular}

\begin{tabular}{|c|c|c|c|c|c|c|c|}
\hline $\mathrm{Pb} 5.2 \mathrm{pH}=4.59$ & $\mathrm{~Pb}-\mathrm{O}$ & 2 & $2.38(0.04)$ & $0.009(0.007)$ & $-0.8(3.6)$ & 1 & 4.0 \\
\hline $30 \mu \mathrm{M} \mathrm{Pb}$ & $\mathrm{Pb}-\mathrm{O} 2$ & 4 & $2.62(0.07)$ & $0.027(0.018)$ & & & \\
\hline $3 \mathrm{mM} \mathrm{Fe}$ & $\mathrm{Pb} \cdots \mathrm{Fe}$ & 1 & $3.39(0.06)$ & $0.008(0.005)$ & & & \\
\hline $\mathrm{Pb} 7.2 \mathrm{pH}=4.04$ & $\mathrm{~Pb}-\mathrm{O}$ & 2 & $2.38(0.03)$ & $0.013(0.070)$ & $-3.1(3.5)$ & 1 & 1.1 \\
\hline $30 \mu \mathrm{M} \mathrm{Pb}$ & $\mathrm{Pb}-\mathrm{O} 2$ & 4 & $2.60(0.08)$ & $0.031(0.016)$ & & & \\
\hline $3 \mathrm{mM} \mathrm{Fe}$ & $\mathrm{Pb} \cdots \mathrm{Fe} 1$ & $0.40(0.40)$ & $3.43(0.10)$ & 0.008 & & & \\
\hline $600 \mu \mathrm{M} P$ & $\mathrm{~Pb} \cdots \mathrm{Fe} 2$ & 0.60 & $4.04(0.09)$ & $0.007(0.013)$ & & & \\
\hline $\mathrm{Pb} 8 \mathrm{pH}=5.16$ & $\mathrm{~Pb}-\mathrm{O}$ & 2 & $2.36(0.03)$ & $0.011(0.003)$ & $-1.1(2.5)$ & 1 & 4.2 \\
\hline $30 \mu \mathrm{M} \mathrm{Pb}$ & $\mathrm{Pb}-\mathrm{O} 2$ & 4 & $2.62(0.04)$ & $0.026(0.008)$ & & & \\
\hline $0.3 \mathrm{mM} \mathrm{Fe}$ & $\mathrm{Pb} \cdots \mathrm{Fe} 1$ & 1 & $3.40(0.04)$ & $0.013(0.005)$ & & & \\
\hline $\mathrm{Pb} 9 \mathrm{pH}=4.68$ & $\mathrm{~Pb}-\mathrm{O}$ & 2 & $2.33(0.05)$ & $0.011(0.004)$ & $-8.1(3.2)$ & 1 & 1.5 \\
\hline $30 \mu \mathrm{M} \mathrm{Pb}$ & $\mathrm{Pb}-\mathrm{O} 2$ & 4 & $2.56(0.07)$ & $0.006(0.008)$ & & & \\
\hline $0.3 \mathrm{mM} \mathrm{Fe}$ & $\mathrm{Pb} \cdots \mathrm{Fe} 1$ & $0.46(0.61)$ & $3.36(0.10)$ & 0.013 & & & \\
\hline $60 \mu \mathrm{M} P$ & $\mathrm{~Pb} \cdots \mathrm{Fe} 2$ & 0.54 & $4.03(0.10)$ & $0.010(0.020)$ & & & \\
\hline
\end{tabular}

${ }^{a} \mathrm{CN}=$ Coordination number; $\mathrm{R}=$ Atomic distance; $\sigma^{2}=$ Debye-Waller factor; $\Delta E=$ Energy shift parameter; $S_{0}{ }^{2}=$ Passive amplitude reduction factor; $R$-factor $=$ goodness-of-fit parameter of the Fourier Transform; sum of the squares of the differences between the data and the fit at each data point, divided by the sum of the squares of the data at each corresponding point. In general, R-factor values less than $5 \%$ are considered to reflect a reasonable fit. Parameters in italics were constrained during fitting. $\mathrm{CN}$ of the $\mathrm{Pb} \cdots \mathrm{Fe} 2$ paths were defined as 1 $\mathrm{CN}$ of $\mathrm{Pb} \cdots \mathrm{Fe} 1$ paths. Uncertainties of fitted parameters as given in Artemis (Ravel and Newville,2005). 

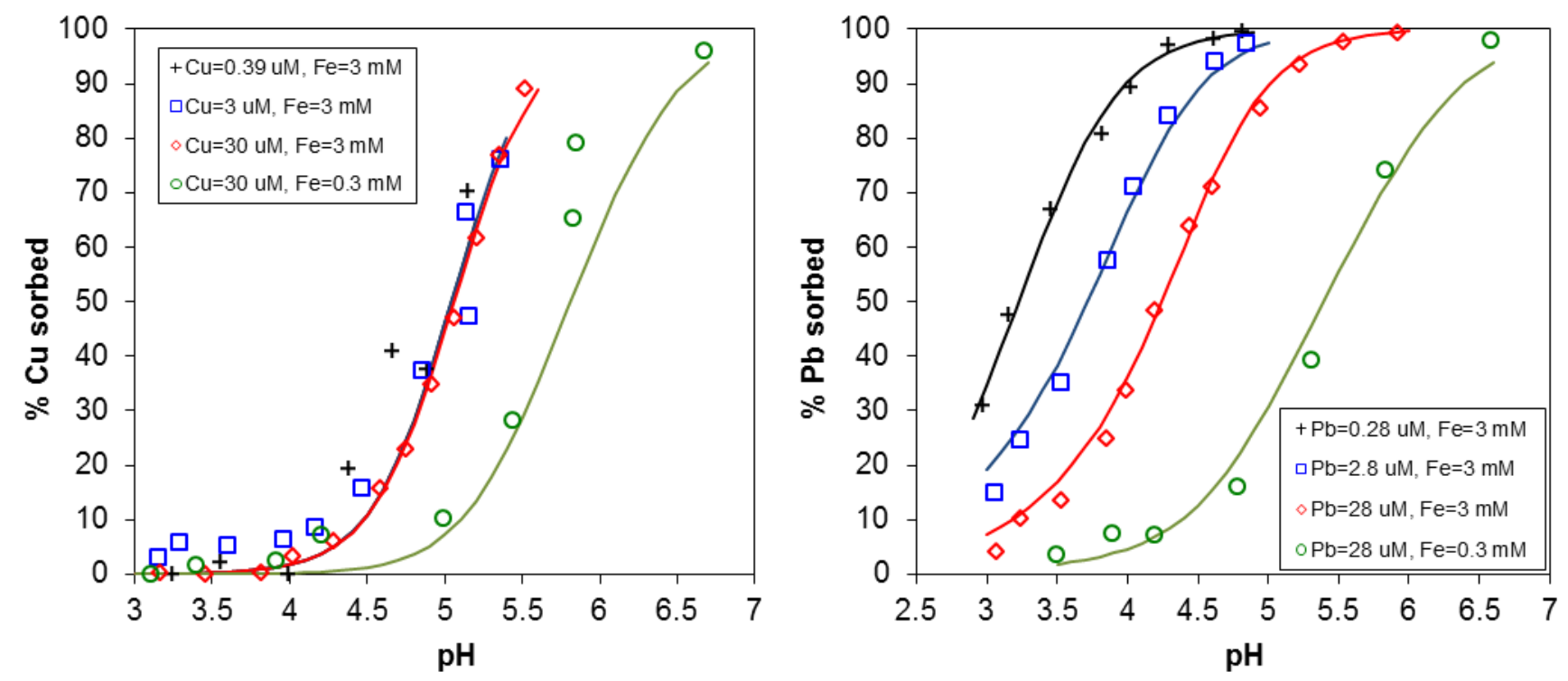

Figure 1. Copper(II) (1a) and lead(II) (1b) adsorption to ferrihydrite. Results from batch experiments (symbols) and from CD-MUSIC modeling with the optimized parameters of Table 1 (lines). The $\mathrm{Cu} / \mathrm{Fe}$ and $\mathrm{Pb} / \mathrm{Fe}$ ratios were approximately $0.0001,0.001,0.01$ and $0.1 . \mathrm{NaNO}_{3}$ concentration $0.01 \mathrm{M}$. 

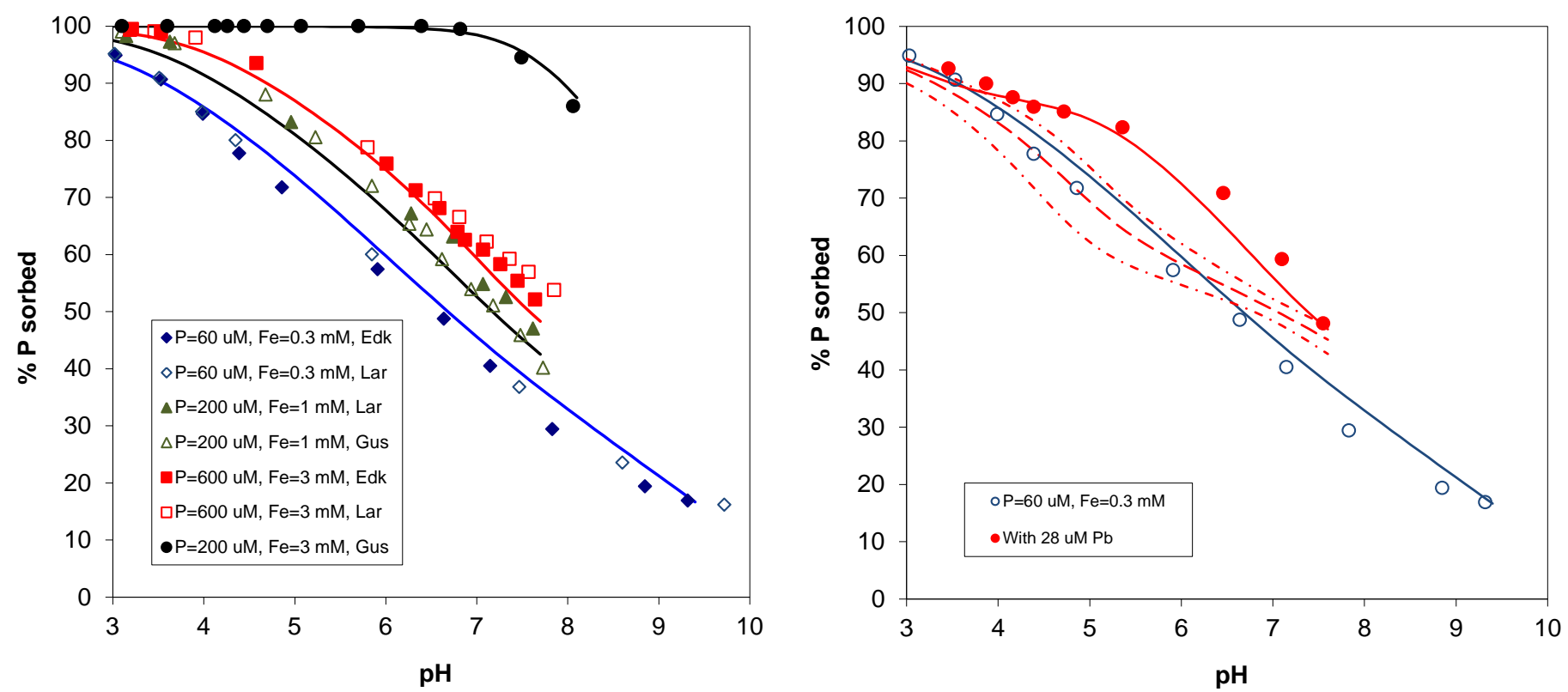

Figure 2. Results from batch experiments with phosphate and ferrihydrite (symbols) and from the CDMUSIC modeling with the optimized parameters of Table 1 (solid lines). The abbreviations "Edk" and "Lar" refer to different batches of this study, whereas "Gus" refers to data of Gustafsson (2003; see also Table S3, Electronic Annex). On the right, phosphate adsorption in a system without and with added lead(II) is shown. The dashed lines represent the CD-MUSIC model prediction with model 1 , and its $95 \%$ confidence interval and the solid red line model 2 . 

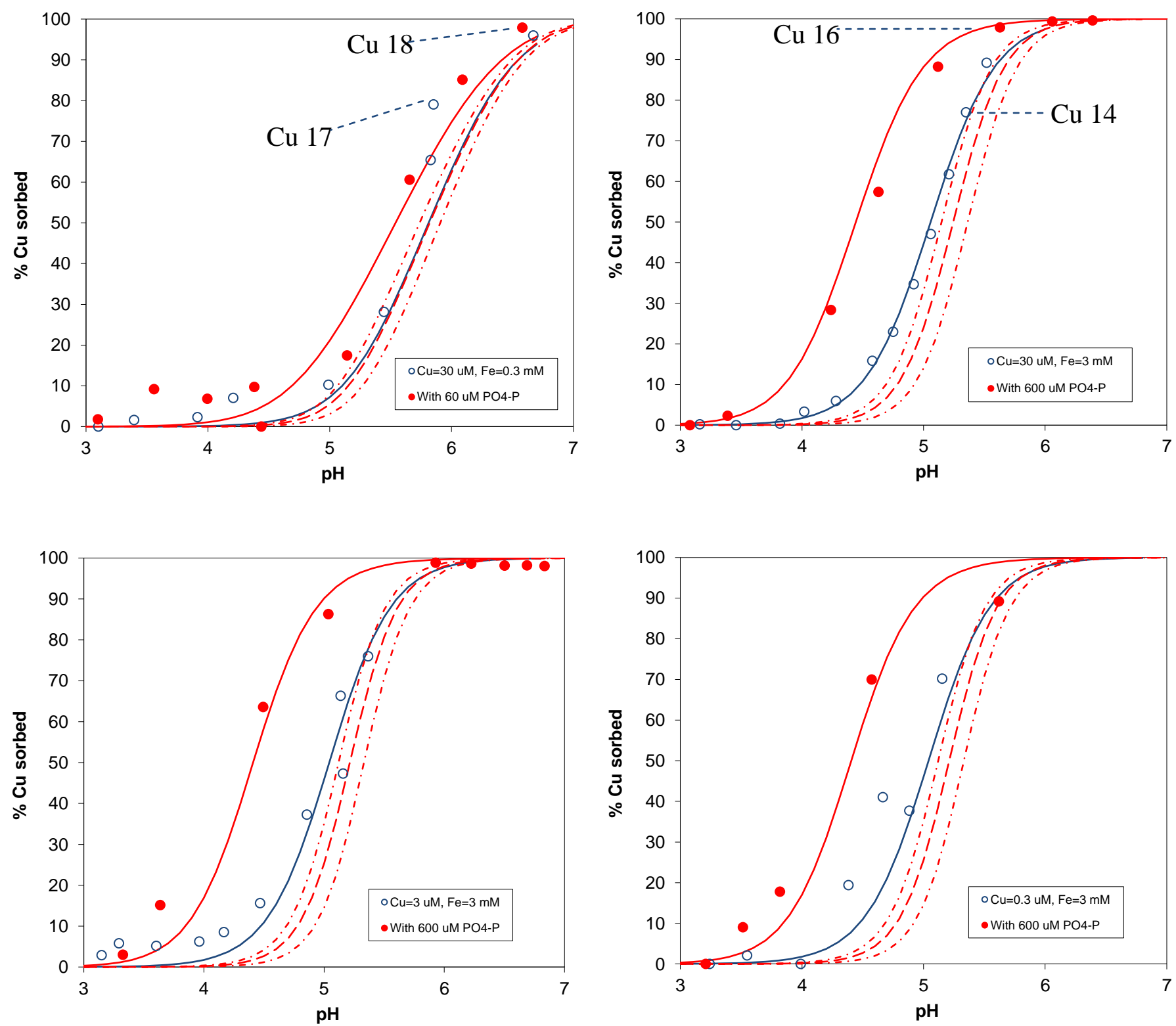

Figure 3. Results from batch experiments with copper(II) and ferrihydrite (symbols) and from the CDMUSIC modeling with the optimized parameters of model 2 (Table 1; solid lines), samples with addition of phosphate (filled circles) and without addition of phosphate (empty circles). $\mathrm{NaNO}_{3}$ concentration $0.01 \mathrm{M}$. The model prediction with model 1 for the ternary system, with its $95 \%$ confidence interval, is shown as dashed lines. Positions of the four samples for EXAFS analysis are marked in the two upper plots. 

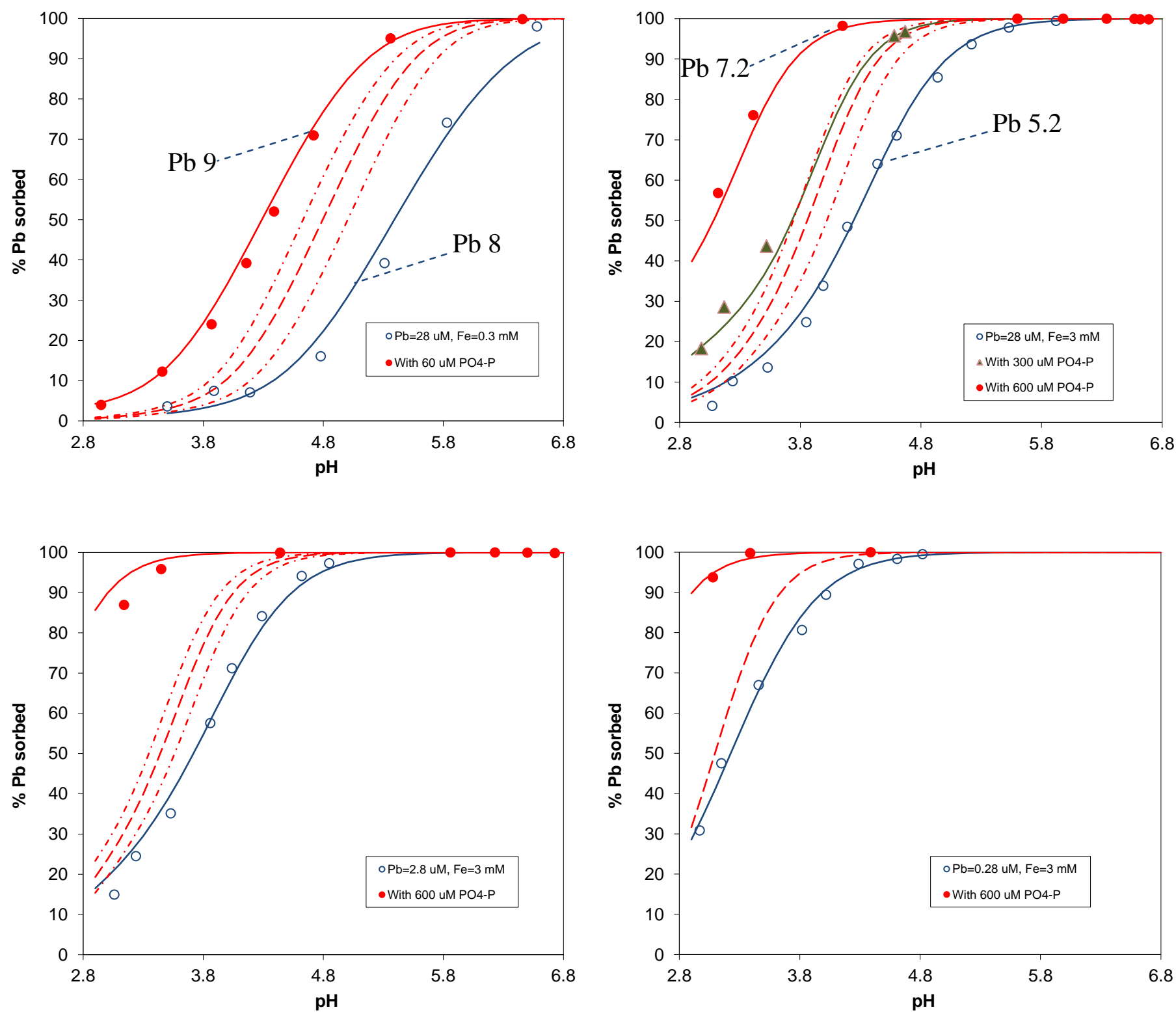

Figure 4. Results from batch experiments with lead(II) and ferrihydrite (symbols) and from the CDMUSIC modeling with the optimized parameters of model 2 (Table 1; solid lines), samples with addition of phosphate (filled circles) and without addition of phosphate (empty circles). $\mathrm{NaNO}_{3}$ concentration is $0.01 \mathrm{M}$. The model prediction with model 1 for the ternary system, with its $95 \%$ confidence interval, is shown as dashed lines. The $95 \%$ confidence interval was not available at the lowest $\mathrm{Pb} / \mathrm{Fe}$ ratio (see Electronic Annex). Positions of the four samples for EXAFS analysis are marked in the two upper plots. 

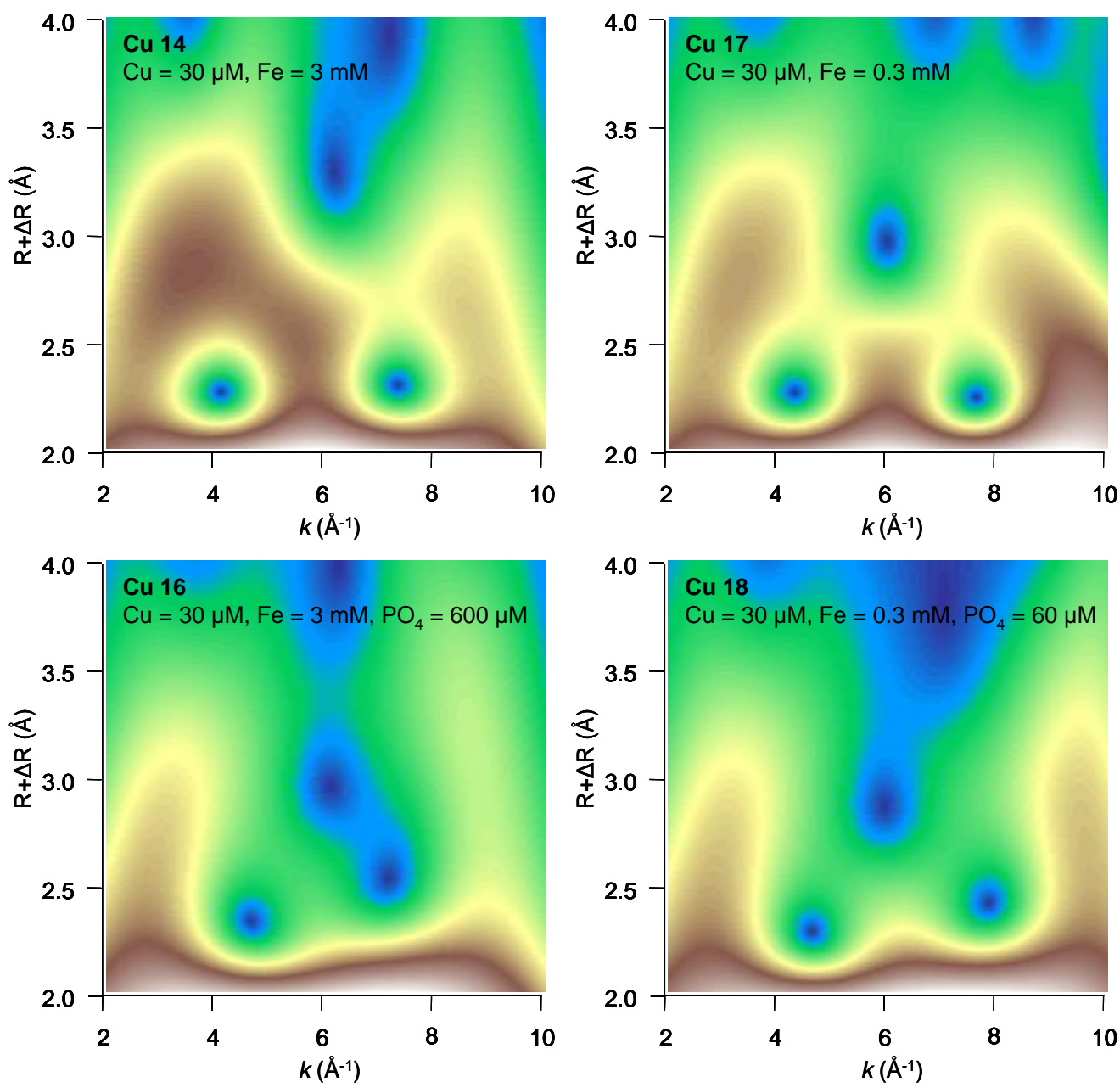

Figure 5. Results from Wavelet transform analysis of copper(II) EXAFS spectra. K-range used was 2.7-9 $\AA^{-1}$ for Cu 14 and $\mathrm{Cu} 16,2.7-10.5 \AA^{-1}$ for $\mathrm{Cu} 17$ and 2.7-10 $\AA^{-1}$ for Cu 18. X-axis $(k)$ indicates energy expressed as the photoelectron wavenumber and $y$-axis $(r)$ is not corrected for phase shift. White/brown areas indicate high intensity whereas blue/green areas indicate low intensity of the WT modulus. Below $\mathrm{R}+\Delta \mathrm{R}=2.3 \AA$ the high intensity is contributions from $\mathrm{Cu}-\mathrm{O}$ distances at all $\mathrm{k}$. 

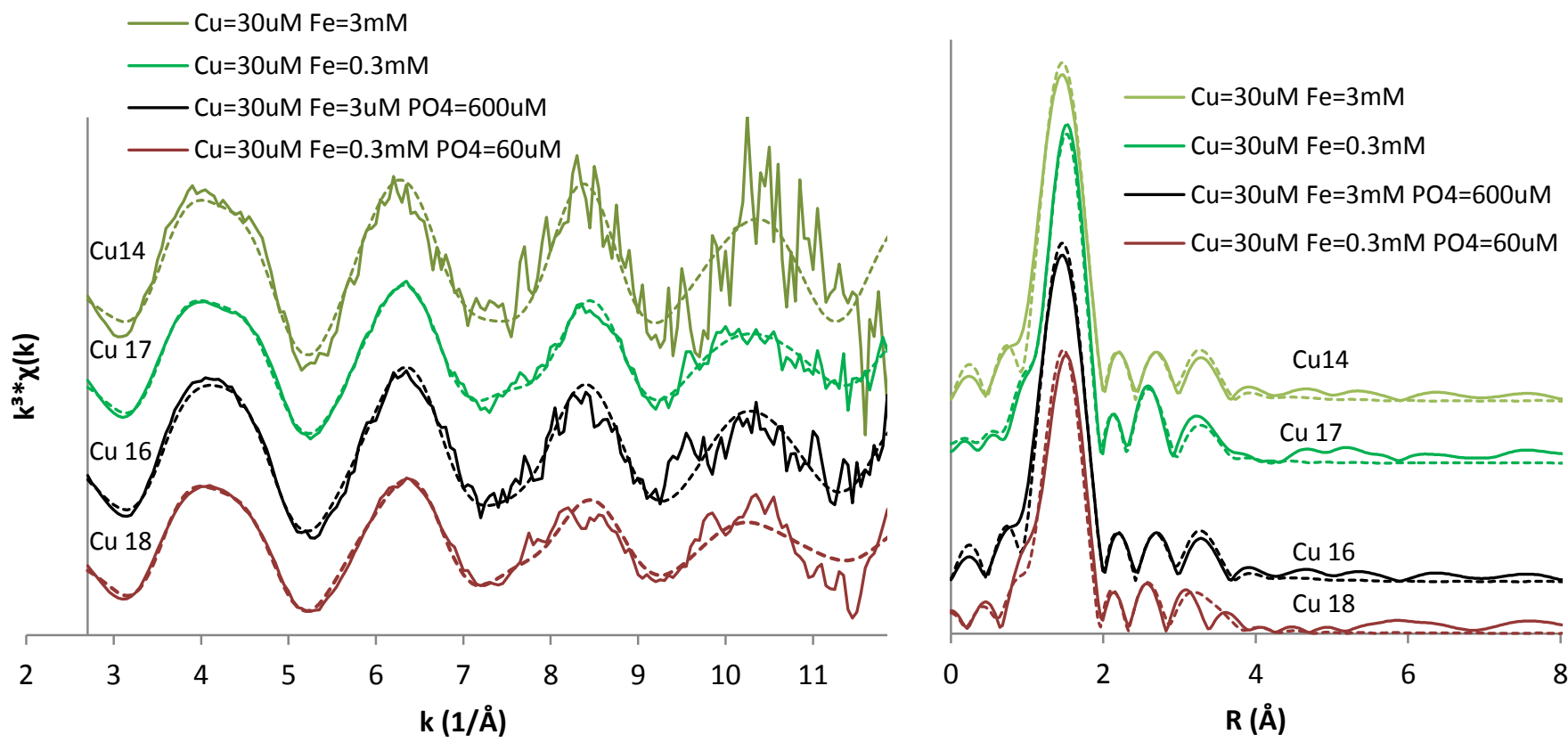

Figure 6. Left: $k_{3}$-weighted EXAFS spectra for copper(II) in ferrihydrite samples with and without phosphate. Lines are raw data and dashed lines are best fits. Right: Fourier Transforms (FT magnitudes) of the $k_{3}$-weighted EXAFS spectra. Lines are raw data and dashed lines are best fits. 

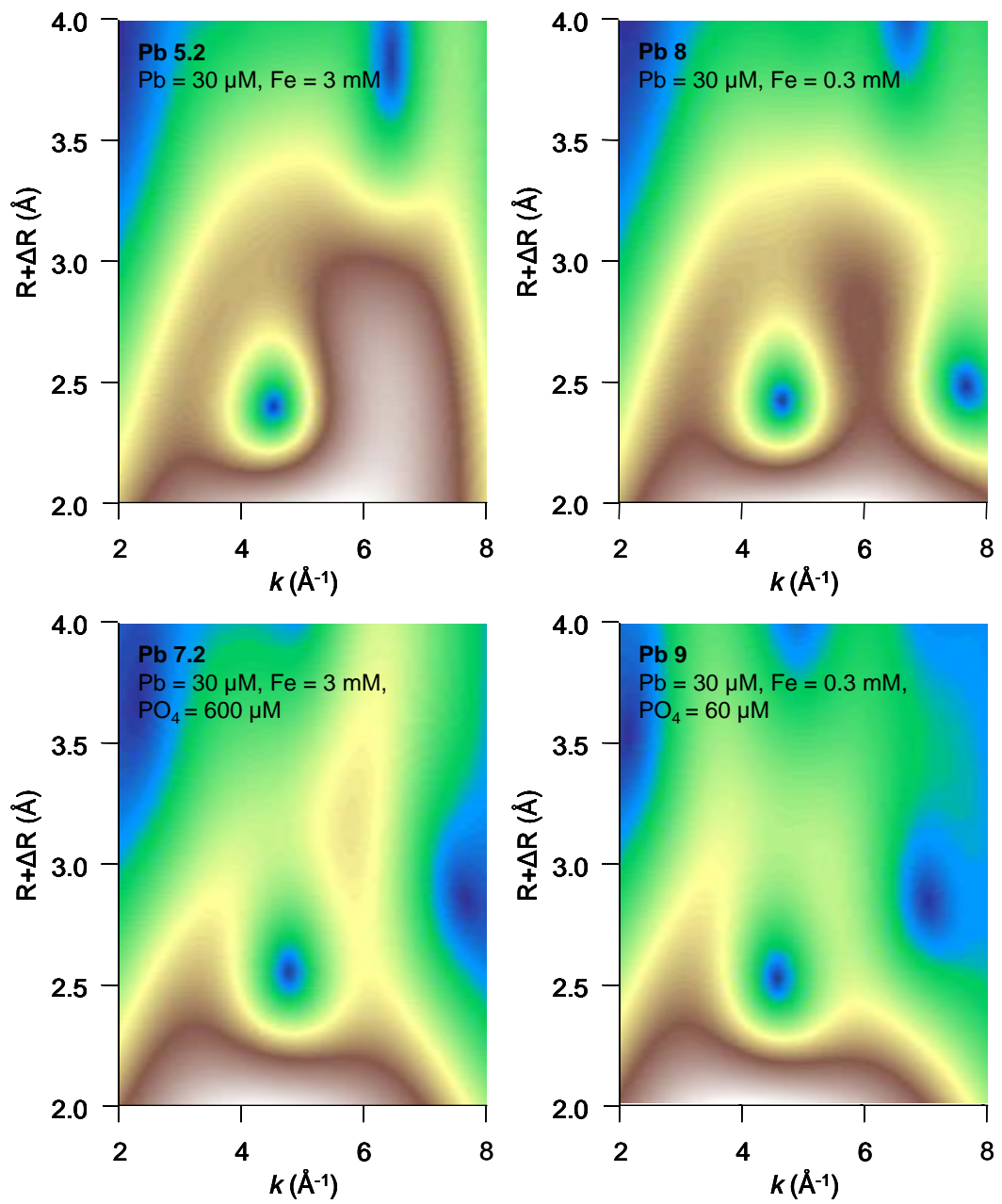

Figure 7. Results from Wavelet transform analysis of lead(II) EXAFS spectra. $K$-range used was 2.25-8 $\AA^{-1}$ for spectra Pb 5.2, Pb 7.2, and Pb 9, and 2.25-9 $\AA^{-1}$ for Pb 8. X-axis $(k)$ indicates energy expressed as the photoelectron wavenumber and $y$-axis $(r)$ is not corrected for phase shift.

White/brown areas indicate high intensity whereas blue/green areas indicate low intensity of the WT modulus. Below $\mathrm{R}+\Delta R=2.3 \AA$ the high intensity is contributions from $\mathrm{Pb}-\mathrm{O}$ distances at all $\mathrm{k}$. 

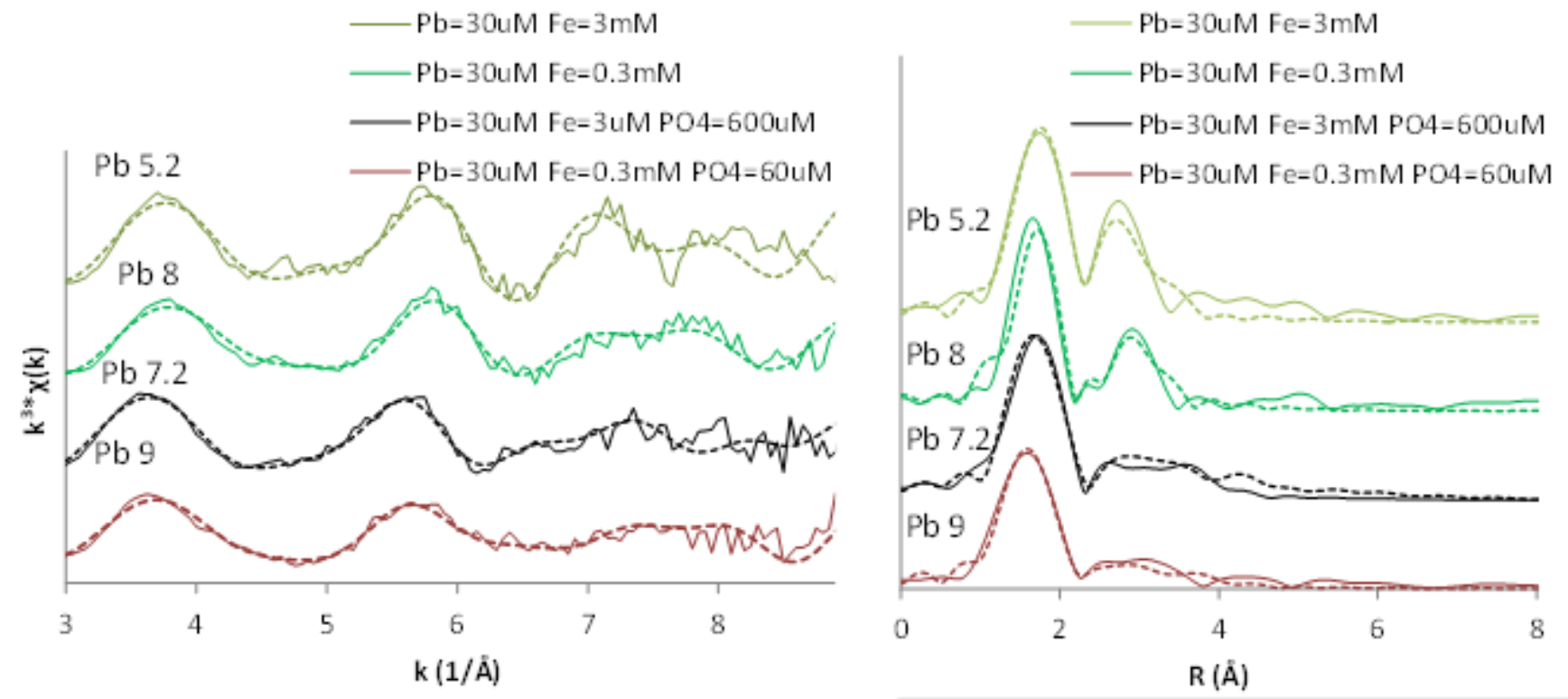

Figure 8. Left: $k_{3}$-weighted EXAFS spectra for lead(II) in ferrihydrite samples with and without phosphate. Lines are raw data and dashed lines are best fits. Right: Fourier Transforms (FT magnitudes) of the $k_{3}$-weighted EXAFS spectra. Lines are raw data and dashed lines are best fits. 


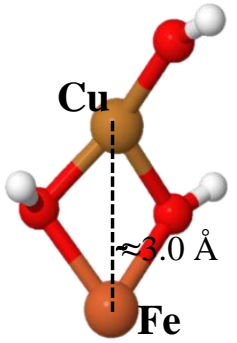

A. Edge-sharing

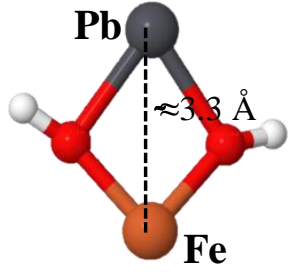

E. Edge-sharing $(\mathrm{FeOH})_{2} \mathbf{P b}^{+}$

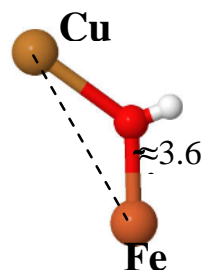

B. Monodentate $\mathrm{FeOHCu}^{+1.5}$

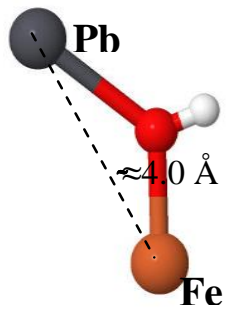

F. Monodentate $\mathrm{FeOHPb}^{+1.5}$

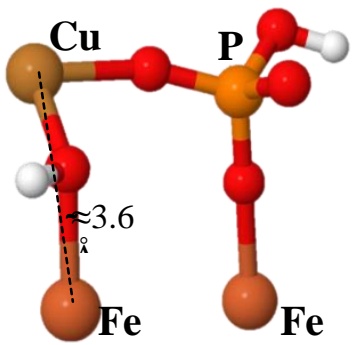

C. Ternary monodentate $(\mathrm{FeO})_{2} \mathrm{HCuPO}_{3} \mathrm{H}^{\mathbf{0}}$

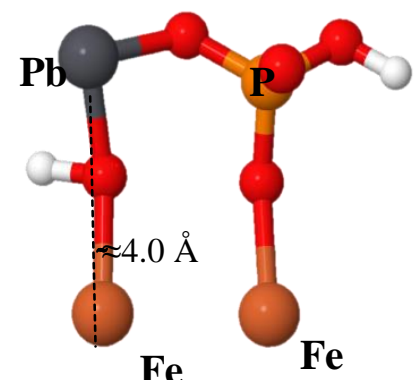

G. Ternary monodentate $(\mathrm{FeO})_{2} \mathrm{HPbPO}_{3} \mathrm{H}^{0}$

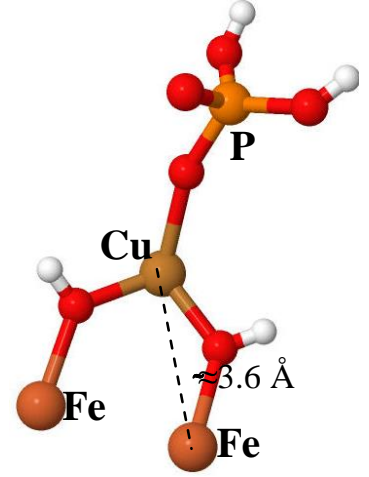

D. Ternary corner-sharing $(\mathrm{FeOH})_{2} \mathrm{CuPO}_{4} \mathrm{H}_{2}{ }^{0}$

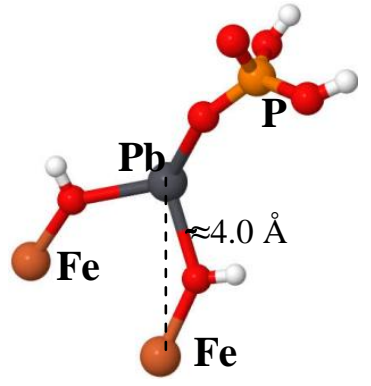

H. Ternary corner-sharing $(\mathrm{FeOH})_{2} \mathrm{PbPO}_{4} \mathrm{H}_{2}{ }^{\mathrm{O}}$

Figure 9. Structures of copper(II) and lead(II) complexes discussed in the text as described in the CDMUSIC model. Red is oxygen and white hydrogen, iron, copper(II), lead(II) and phosphorus are marked in the figures along with the $\mathrm{Cu} \cdots \mathrm{Fe} / \mathrm{Pb} \cdots$ Fe distances from interpretation of EXAFS spectra. 

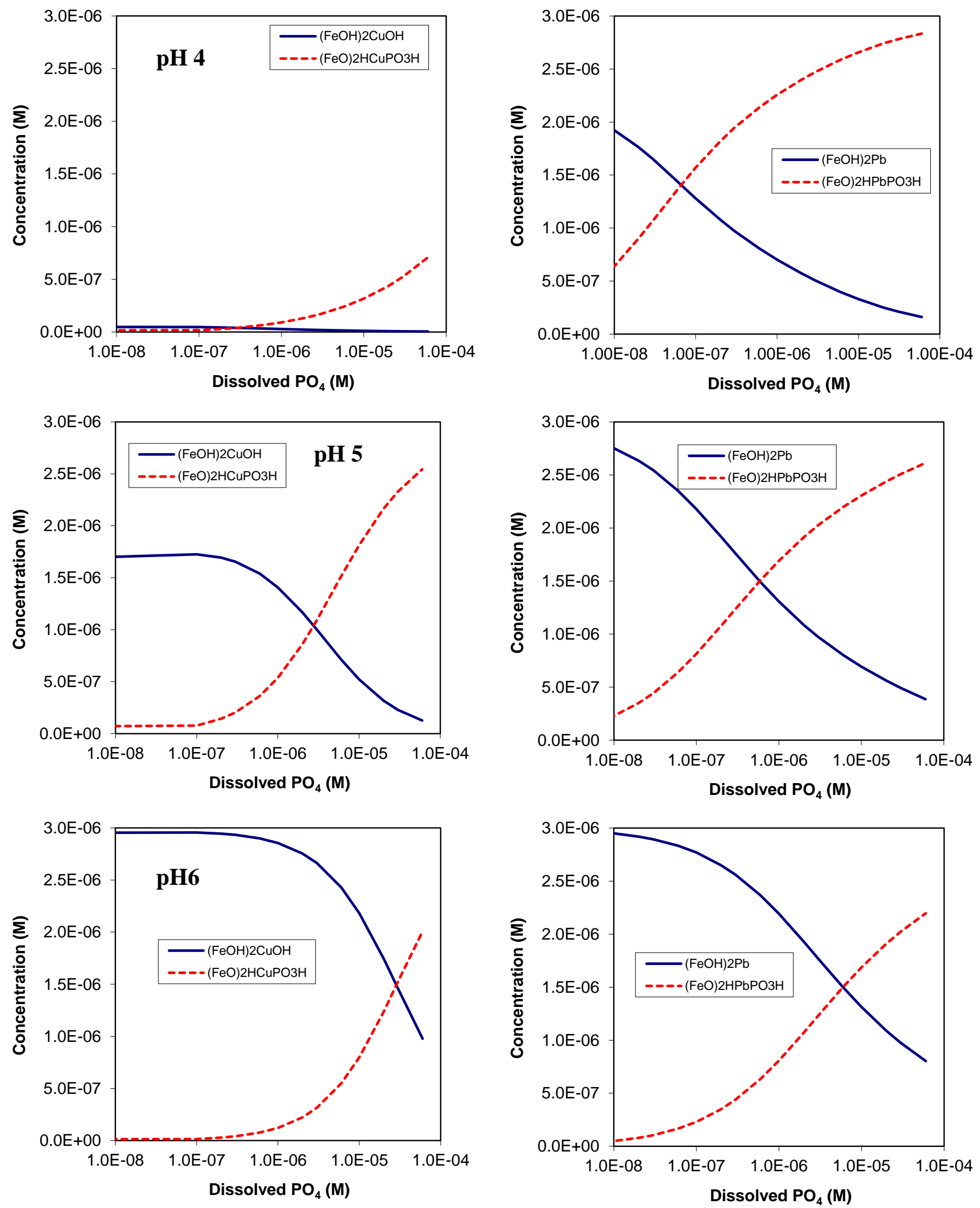

Figure 10. Concentrations of different surface complexes as a function of the total dissolved phosphate concentration at $\mathrm{pH} 4,5$ and 6 under the following conditions: total $\mathrm{Fe}=3 \mathrm{mM}$, total metal: $3 \mu \mathrm{M}$, background electrolyte $=0.01 \mathrm{M} \mathrm{NaNO}_{3}$. Left column: copper(II); right column: lead(II). 


\title{
Phosphate effects on copper(II) and lead(II) sorption to ferrihydrite
}

\author{
Charlotta Tiberg, Carin Sjöstedt, Ingmar Persson, Jon Petter Gustafsson
}

\section{$\underline{\text { Electronic annex }}$}

\section{Contents}

Fig. S1. Surface charge of ferrihydrite at three different $\mathrm{NaNO}_{3}$ concentrations.

Fig. S2. Fit of the optimized surface complexation model to the copper(II) adsorption data of Swedlund and Webster (2001) and to the data of Benjamin and Leckie $(1981,1982)$.

Fig. S3. Fit of the optimized surface complexation model to the lead(II) adsorption data of Swedlund et al. (2003) and to the data of Benjamin and Leckie $(1981,1982)$.

Table S1. Equilibrium constants and heats of reaction for lead(II)- and copper(II)-containing soluble complexes and solid phases considered in the modeling.

Table S2. Data sets used for optimization of copper(II) and lead(II) surface complexation constants for ferrihydrite (Fh).

Table S3. Data sets used for optimization of phosphate surface complexation constants for ferrihydrite $(\mathrm{Fh})$.

Table S4. Intrinsic surface complexation constants for copper(II) adsorption on ferrihydrite.

Table S5. Intrinsic surface complexation constants for lead(II) adsorption on ferrihydrite.

Table S6. Intrinsic surface complexation constants for phosphate adsorption on ferrihydrite.

Model 3: Can the presence of a monodentate complex successfully explain the phosphate effects on lead(II) sorption? (Text with three additional figures.) 


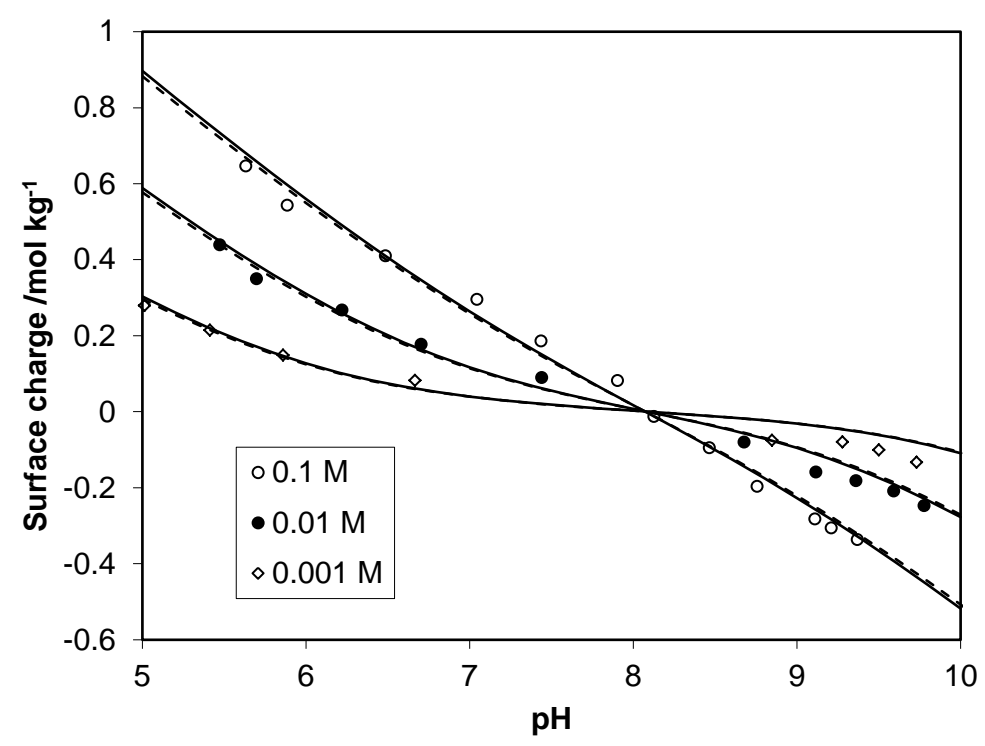

Fig. S1. Surface charge of ferrihydrite at three different $\mathrm{NaNO}_{3}$ concentrations. Data reported by Hsi and Langmuir (1985) are shown as points, whereas the solid line is the model fit of the surface complexation model used in this study, with a specific surface area of $650 \mathrm{~m}^{2} \mathrm{~g}^{-1}$, with inner-layer and outer-layer capacitances of 1.15 and $0.9 \mathrm{C} \mathrm{m}^{-2}$, with a total site density of 7.8 sites $\mathrm{nm}^{-2}$, and with the electrolyte ion-binding constants reported in Table 2. The dashed line represents the model fit with the same model, when the site density is instead set to 7.2 sites $\mathrm{nm}^{-2}$, i.e. as in the model of Hiemstra and van Riemsdijk (2009). 

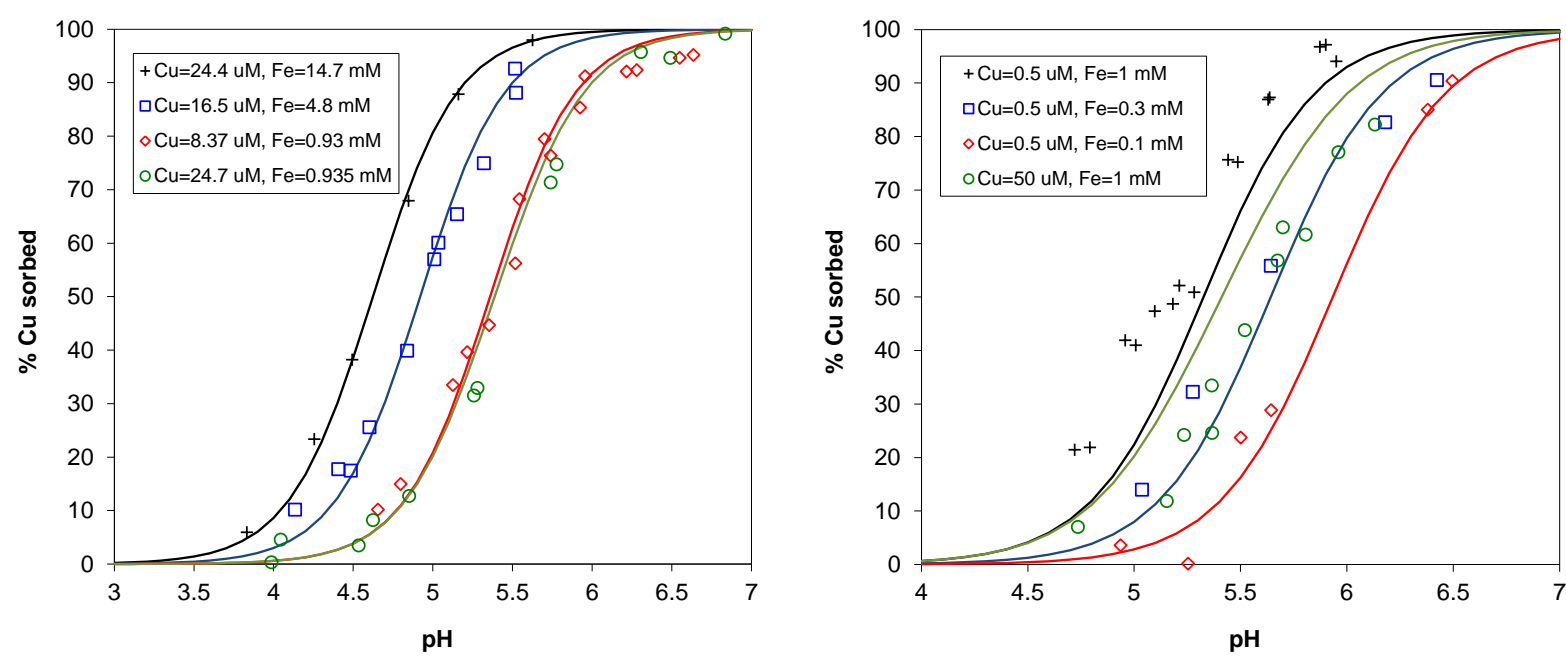

Fig. S2. Fit of the optimized surface complexation model to the copper(II) adsorption data of Swedlund and Webster (2001; left) and to the data of Benjamin and Leckie (1981, 1982; right).
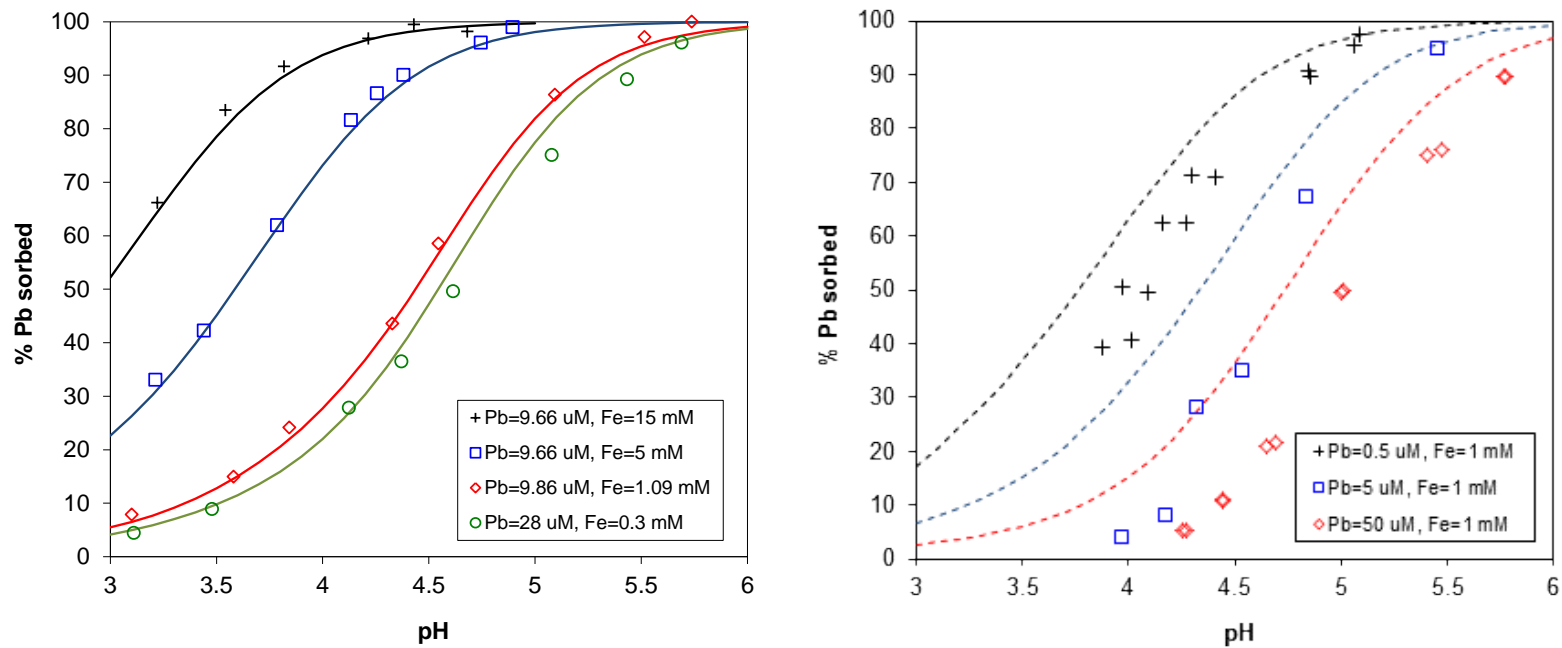

Fig. S3. Fit of the optimized surface complexation model to the lead(II) adsorption data of Swedlund et al. (2003; left) and to the data of Benjamin and Leckie (1981, 1982; right). For the latter data set the model fits are shown as dashed lines, as these data were not used for the calculation of weighted averages. 
Table S1

Equilibrium constants and heats of reaction for lead(II)- and copper(II)-containing soluble complexes and solid phases considered in the modeling.

\begin{tabular}{|c|c|c|c|}
\hline Reaction & $\log K\left(25^{\circ} \mathrm{C}\right)$ & $\Delta H_{\mathrm{r}}^{0}\left(\mathrm{~kJ} \mathrm{~mol}^{-1}\right)$ & Source \\
\hline \multicolumn{4}{|l|}{ Complexes } \\
\hline $\mathrm{Cu}^{2+}+\mathrm{H}_{2} \mathrm{O} \leftrightarrow \mathrm{CuOH}^{+}+\mathrm{H}^{+}$ & -7.497 & 35.81 & NIST $^{b}$ \\
\hline $\mathrm{Cu}^{2+}+2 \mathrm{H}_{2} \mathrm{O} \leftrightarrow \mathrm{Cu}(\mathrm{OH})_{2}{ }^{0}+2 \mathrm{H}^{+}$ & -16.23 & 93.1 & Plyasunova et al. (1997) \\
\hline $\mathrm{Cu}^{2+}+\mathrm{NO}_{3}^{-} \leftrightarrow \mathrm{CuNO}_{3}^{+}$ & 0.5 & -4.1 & NIST $^{b}$ \\
\hline $\mathrm{Cu}^{2+}+\mathrm{H}^{+}+\mathrm{PO}_{4}^{3-} \leftrightarrow \mathrm{CuHPO}_{4}{ }^{3-}$ & 16.5 & $0^{\mathrm{a}}$ & NIST $^{b}$ \\
\hline $\mathrm{Pb}^{2+}+\mathrm{H}_{2} \mathrm{O} \leftrightarrow \mathrm{PbOH}^{+}+\mathrm{H}^{+}$ & -7.597 & 23.81 & NIST $^{b}$ \\
\hline $\mathrm{Pb}^{2+}+2 \mathrm{H}_{2} \mathrm{O} \leftrightarrow \mathrm{Pb}(\mathrm{OH})_{2}{ }^{0}+2 \mathrm{H}^{+}$ & -17.094 & $0^{\mathrm{a}}$ & NIST $^{b}$ \\
\hline $\mathrm{Pb}^{2+}+\mathrm{NO}_{3}^{-} \leftrightarrow \mathrm{PbNO}_{3}^{+}$ & 1.17 & -2.0 & $\mathrm{NIST}^{\mathrm{b}}$ \\
\hline $\mathrm{Pb}^{2+}+\mathrm{H}^{+}+\mathrm{PO}_{4}^{3-} \leftrightarrow \mathrm{PbHPO}_{4}^{0}$ & 15.475 & $0^{\mathrm{a}}$ & NIST $^{b}$ \\
\hline $\mathrm{Pb}^{2+}+2 \mathrm{H}^{+}+\mathrm{PO}_{4}^{3-} \leftrightarrow \mathrm{PbH}_{2} \mathrm{PO}_{4}^{+}$ & 21.073 & $0^{\mathrm{a}}$ & $\mathrm{NIST}^{\mathrm{b}}$ \\
\hline \multicolumn{4}{|l|}{ Solid phases } \\
\hline $\mathrm{Cu}(\mathrm{OH})_{2}(\mathrm{~s})+2 \mathrm{H}^{+} \leftrightarrow \mathrm{Cu}^{2+}+2 \mathrm{H}_{2} \mathrm{O}$ & 9.29 & -53.12 & NIST $^{b}$ \\
\hline $\mathrm{Cu}_{3}\left(\mathrm{PO}_{4}\right)_{2} \times 3 \mathrm{H}_{2} \mathrm{O}(\mathrm{s}) \leftrightarrow 3 \mathrm{Cu}^{2+}+2 \mathrm{PO}_{4}{ }^{3-}+3 \mathrm{H}_{2} \mathrm{O}$ & -35.12 & $0^{\mathrm{a}}$ & MINTEQA2 $^{d}$ \\
\hline $\mathrm{Pb}(\mathrm{OH})_{2}(\mathrm{~s})+2 \mathrm{H}^{+} \leftrightarrow \mathrm{Pb}^{2+}+2 \mathrm{H}_{2} \mathrm{O}$ & 8.15 & -58.5 & MINTEQA2 $^{\mathrm{d}}$ \\
\hline $\mathrm{PbHPO}_{4}(\mathrm{~s}) \leftrightarrow \mathrm{Pb}^{2+}+\mathrm{H}^{+}+\mathrm{PO}_{4}^{3-}$ & -23.8 & $0^{\mathrm{a}}$ & $\mathrm{NIST}^{\mathrm{b}}$ \\
\hline $\mathrm{Pb}_{5}\left(\mathrm{PO}_{4}\right)_{3} \mathrm{OH}(\mathrm{s})+\mathrm{H}^{+} \leftrightarrow 5 \mathrm{~Pb}^{2+}+3 \mathrm{PO}_{4}{ }^{3-}+\mathrm{H}_{2} \mathrm{O}$ & -62.79 & $0^{\mathrm{a}}$ & MINTEQA2 $^{\mathrm{d}}$ \\
\hline
\end{tabular}

${ }^{\mathrm{a}}$ Not available, therefore set to 0

${ }^{\mathrm{b}}$ Smith, R.M., Martell, A.E. and Motekaitis, R.J. (2003) NIST crititically selected stability constants of metal complexes database. NIST standard reference database 46, version 7.0. NIST, Gaithersburg, MD, USA.

'Plyasunova, N.V., Wang, M., Zhang, Y. and Muhammed, M. (1997) Critical evaluation of thermodynamics of complex formation of metal ions in aqueous solutions. II. Hydrolysis and hydroxo-complexes of $\mathrm{Cu}^{2+}$ at 298.15 K. Hydrometallurgy 45, 37-51.

'Allison, J.D., Brown, D.S. and Novo-Gradac, K.J. (1991) MINTEQA2/PRODEFA2. A geochemical assessment model for environmental systems, Version 3.0 Users' manual. United States Environmental Protection Agency, Office for Research and Development, Washington DC. 
Table S2

Data sets used for optimization of copper(II) and lead(II) surface complexation constants for ferrihydrite (Fh)

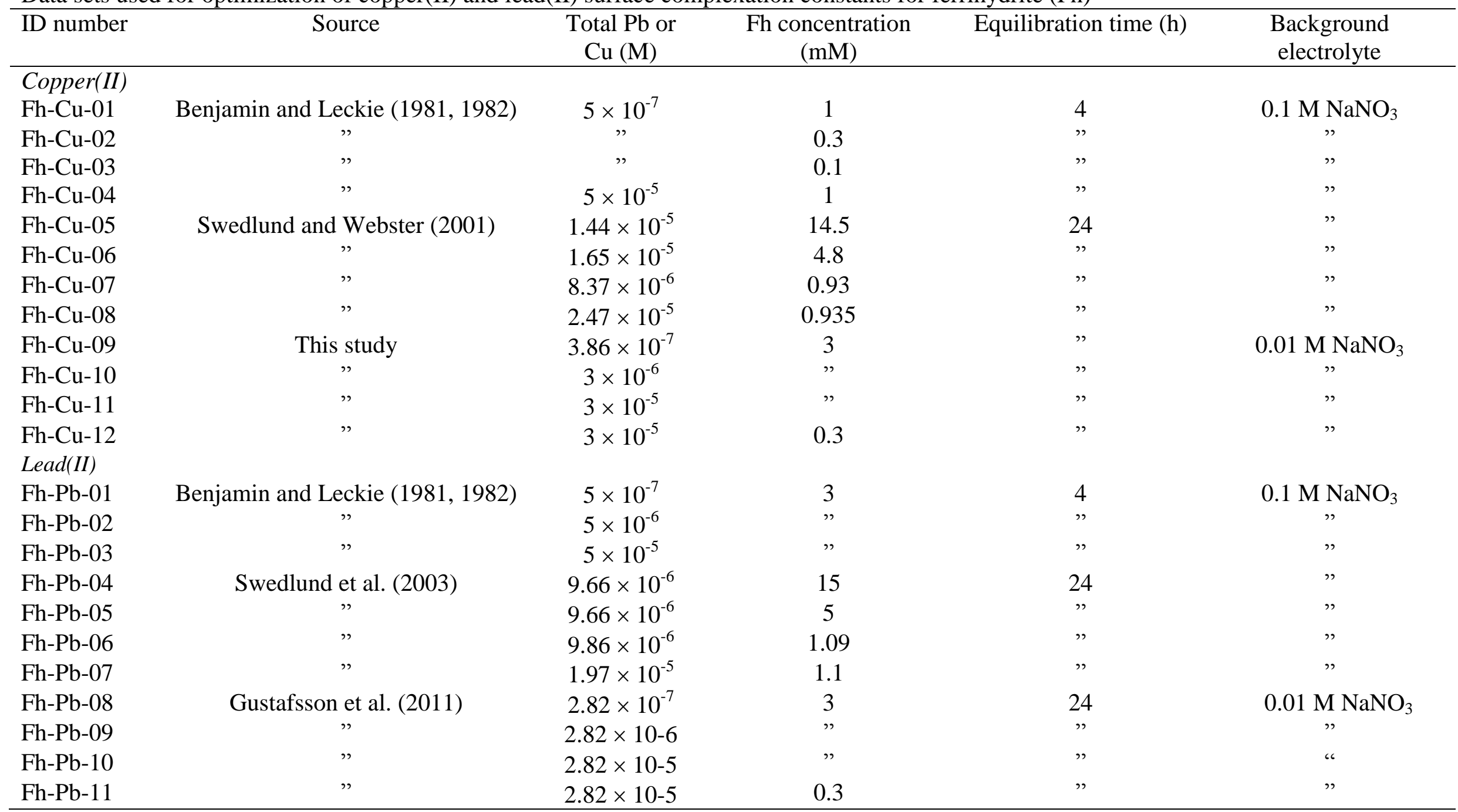


Table S3

Data sets used for optimization of phosphate surface complexation constants for ferrihydrite (Fh)

\begin{tabular}{|c|c|c|c|c|c|}
\hline ID number & Source & Total P (M) & $\begin{array}{l}\text { Fh concentration } \\
(\mathrm{mM})\end{array}$ & Equilibration time (h) & $\begin{array}{l}\text { Background } \\
\text { electrolyte }\end{array}$ \\
\hline Fh-P-01 & Gustafsson (2003) & $2 \times 10^{-4}$ & 1 & 24 & $0.01 \mathrm{M} \mathrm{NaNO}_{3}$ \\
\hline Fh-P-03 & This study; batch "Edkymish" & $6 \times 10^{-4}$ & 3 & 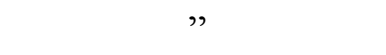 & ” \\
\hline Fh-P-04 & This study; batch "Larsson" & $2 \times 10^{-4}$ & 1 & ” & ” \\
\hline Fh-P-05 & 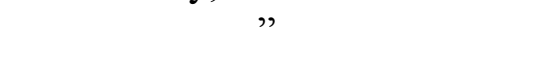 & $6 \times 10^{-5}$ & 0.3 & ” & ” \\
\hline
\end{tabular}


Table S4

Intrinsic surface complexation constants for copper(II) adsorption on ferrihydrite (standard deviations in parentheses). Weighted average equilibrium constants are shown, with the $95 \%$ confidence interval (italics in parentheses).

\begin{tabular}{lcc}
\hline Data set & $\log K,(\mathrm{FeOH})_{2} \mathrm{CuOH}$ & $V_{Y}{ }^{\mathrm{a}}$ \\
\hline Fh-Cu-01 & $1.32(0.011)$ & 5.7 \\
Fh-Cu-02 & $1.04(0.019)$ & 13.6 \\
Fh-Cu-03 & $1.09(0.019)$ & 2.0 \\
Fh-Cu-04 & $0.64(0.011)$ & 4.9 \\
Fh-Cu-05 & $0.73(0.016)$ & 6.3 \\
Fh-Cu-06 & $1.00(0.011)$ & 9.6 \\
Fh-Cu-07 & $0.85(0.010)$ & 25.2 \\
Fh-Cu-08 & $0.85(0.013)$ & 168 \\
Fh-Cu-09 & $1.31(0.018)$ & 9.4 \\
Fh-Cu-10 & $1.03(0.019)$ & 6.8 \\
Fh-Cu-11 & $0.99(0.014)$ & 2.4 \\
Fh-Cu-12 & $1.31(0.021)$ & 16.3 \\
\hline
\end{tabular}

Weighted averages $\quad 0.97(0.95,1.03)$

${ }^{\mathrm{a}}$ Weighted sum of squares, according to Herbelin and Westall (1999) 
Table S5

Intrinsic surface complexation constants for lead(II) adsorption on ferrihydrite (standard deviations in parentheses). Weighted average equilibrium constants are shown, with the $95 \%$ confidence interval (italics in parentheses).

\begin{tabular}{|c|c|c|c|c|}
\hline Data set & $\log K(\mathrm{FeOH})_{2} \mathrm{~Pb}^{+}(99 \%)$ & $\log K,(\mathrm{FeOH})_{2} \mathrm{~Pb}^{+}(0.9 \%)$ & $\log K,(\mathrm{FeOH})_{2} \mathrm{~Pb}^{+}(0.1 \%)$ & $V_{Y}^{\mathrm{a}}$ \\
\hline Fh-Pb-01 ${ }^{b}$ & - & $12.13(0.047)$ & $13.66(0.129)$ & 6.5 \\
\hline $\mathrm{Fh}-\mathrm{Pb}-03^{\mathrm{b}}$ & $9.06(0.010)$ & - & - & 27.8 \\
\hline Fh-Pb-05 & $9.55(0.079)$ & $12.46(0.051)$ & - & 10.9 \\
\hline $\mathrm{Fh}-\mathrm{Pb}-06$ & $9.64(0.021)$ & $12.36(0.043)$ & - & 2.3 \\
\hline Fh-Pb-07 & $9.33(0.015)$ & $12.07(0.044)$ & - & 2.1 \\
\hline $\mathrm{Fh}-\mathrm{Pb}-10$ & $9.58(0.015)$ & $12.20(0.024)$ & - & 7.2 \\
\hline Fh-Pb-11 & $9.80(0.015)$ & - & - & 4.2 \\
\hline
\end{tabular}

Weighted averages

$9.58(9.48,9.69)$

$12.25(12.16,12.35)$

$14.24^{\mathrm{C}}$

${ }^{a}$ Weighted sum of squares, according to FITEQL (Herbelin and Westall, 1999)

${ }^{\mathrm{b}}$ These data sets were not used for calculation of the weighted averages as the data showed consistently weaker binding compared to the two other data sets (see also main text)

${ }^{\mathrm{c}}$ No confidence interval could be defined 
Table S6

Intrinsic surface complexation constants for phosphate adsorption on ferrihydrite (standard deviations in parentheses). Weighted average equilibrium constants are shown, with the $95 \%$ confidence interval (italics in parentheses).

\begin{tabular}{|c|c|c|c|c|}
\hline Data set & $\log K(\mathrm{FeOH})_{2} \mathrm{PO}_{2}^{-}$ & $\log K,(\mathrm{FeOH})_{2} \mathrm{POOH}$ & $\log K, \mathrm{FeOPO}_{3} \mathrm{H}_{2}$ & $V_{Y}^{\mathrm{a}}$ \\
\hline Fh-P-01 & $27.45(0.071)$ & $32.89(0.025)$ & $30.26(0.035)$ & 0.61 \\
\hline Fh-P-02 & $28.92(0.098)$ & $33.31(0.027)$ & $30.57(0.043)$ & 0.21 \\
\hline Fh-P-03 & $27.53(0.057)$ & $32.58(0.036)$ & $30.22(0.028)$ & 227 \\
\hline Fh-P-05 & $27.13(0.033)$ & $31.95(0.075)$ & $30.11(0.033)$ & 182 \\
\hline Fh-P-06 & $27.56(0.057)$ & $32.66(0.052)$ & $30.01(0.043)$ & 5.16 \\
\hline Weighted averages & $27.59(27.35,27.83)$ & $32.89(32.71,33.06)$ & $30.23(30.15,30.30)$ & \\
\hline
\end{tabular}

${ }^{\mathrm{a}}$ Weighted sum of squares, according to Herbelin and Westall (1999) 


\section{Model 3: can the presence of a monodentate complex successfully explain the phosphate effects on lead(II) sorption?}

\section{The idea behind model 3}

In systems with only ferrihydrite and $\mathrm{Pb}^{2+}$, edge-sharing bidentate complexes predominate. This is what the EXAFS results show. With the EXAFS results at hand, we cannot exclude the presence of a minor contribution from a monodentate complex ( $<30 \%$ of the total). Such a small contribution would not be easily identified in an EXAFS spectrum.

When $\mathrm{PO}_{4}$ is added, however, monodentate complexes may become predominant, thus explaining the longer $\mathrm{Pb} \cdots \mathrm{Fe}$ distances found in the EXAFS spectra without the need to invoke any ternary surface complexes.

\section{The monodentate complex}

For a monodentate complex to behave in the way described above, it needs to be strongly involved in electrostatic interactions with the oxide surface. In other words, the increased negative charge brought about by sorbing $\mathrm{PO}_{4}$ ions should increase the sorption of the monodentate complex strongly, more strongly than that of the edge-sharing bidentate complex. Therefore in the simulations described below, we did not consider any ternary surface complex, instead we included the following surface complexation reaction into the Visual MINTEQ calculations:
Reaction
$\left(\Delta z_{0}, \Delta z_{1}, \Delta z_{2}\right) \quad \log K$
$(0.5,1.5,0)$
7.3
$\mathrm{FeOH}^{1 / 2}+\mathrm{Pb}^{2+} \leftrightarrow \mathrm{FeOHPb}^{+1.5}$

This complex fulfills these requirements as it increases the surface charge with two molar units, and that the $\Delta z_{1}$ value is relatively high. The CD values $\left(\Delta z_{0}, \Delta z_{1}\right)$ are what would be expected for a complex that causes saturation of the surface oxygen. Letting these numbers vary in a realistic range (e.g., $(0.3,1.7)$ to $(0.7 .1 .3))$ does not change the conclusions shown below significantly.

\section{$\underline{\text { Simulations }}$}

The Visual MINTEQ simulations for this system can be set up in a number of ways, depending on what parameter to optimize. In the following simulations we have optimized the $\log K$ value of the monodentate complex so that it fulfills two conditions:

1. It should ideally not comprise more than $30 \%$ of the sorbed $\mathrm{Pb}$ in systems with only ferrihydrite and $\mathrm{Pb}$, since this would be in conflict with the EXAFS results.

2. The $\log K$ value should provide the best possible fit to dissolved $\mathrm{Pb}$ in the $\mathrm{Pb}-\mathrm{PO}_{4}-\mathrm{Fh}$ systems.

Moreover, we performed the simulations only for the two systems with the highest $\mathrm{Pb} / \mathrm{Fe}$ ratios, since in both these systems the low-affinity $\mathrm{Pb}$ surface complex (i.e. the one with $\log \mathrm{K}$ $=9.58$ in Table 2) predominates. 
$\underline{\text { Results }}$
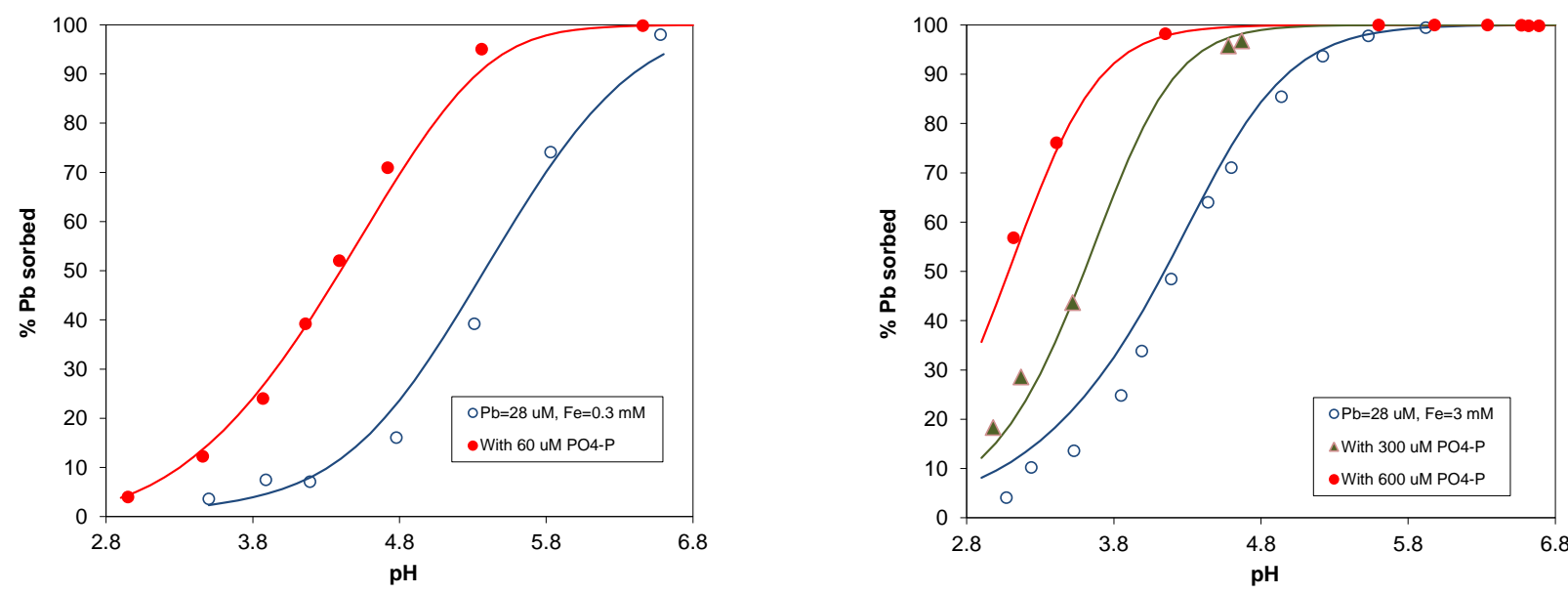

Fig. S4. Percent $\mathrm{Pb}^{2+}$ adsorption as a function of the $\mathrm{pH}$ value and at different $\mathrm{PO}_{4}$ concentrations. Left: $\mathrm{Pb}=28.2 \mu \mathrm{M}, \mathrm{Fe}=0.3 \mathrm{mM}$; Right: $\mathrm{Pb}=28.2 \mu \mathrm{M}, \mathrm{Fe}=3 \mathrm{mM}$. The lines are model fits assuming a combination of edge-sharing bidentate and monodentate complexes as described in the text.

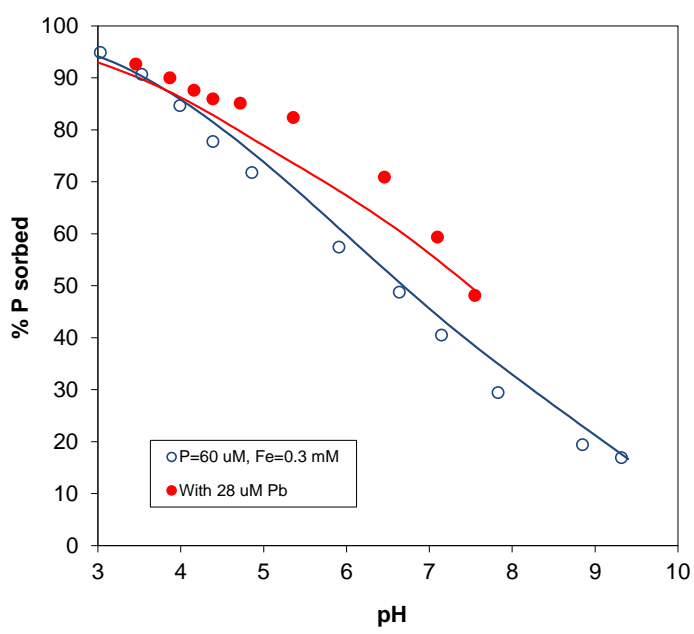

Fig. S5. Percent $\mathrm{PO}_{4}$ adsorption as a function of the $\mathrm{pH}$ value in the absence and presence of $\mathrm{Pb} . \mathrm{Pb}=28.2 \mu \mathrm{M}, \mathrm{Fe}=0.3 \mathrm{mM}$. The lines are model fits assuming a combination of edgesharing bidentate and monodentate $\mathrm{Pb}$ complexes as described in the text. Results for the lower $\mathrm{Pb} / \mathrm{Fe}$ ratio are not shown here because neither the results nor the model indicate a significant dependence on dissolved $\mathrm{Pb}$.

As Fig. S4 shows, it is indeed possible to construct a model that correctly predicts the $\mathrm{Pb}^{2+}$ adsorption in $\mathrm{PO}_{4}$-containing systems using the assumption that there is a monodentate $\mathrm{Pb}$ complex in the system that increases in importance when $\mathrm{PO}_{4}$ is present. The goodness-of-fit is comparable to the model with ternary surface complexes, although not perfect. However, Fig. S5 shows that the model does not predict $\mathrm{PO}_{4}$ sorption very well in the presence of $\mathrm{Pb}^{2+}$. 
For this system, Model 2 performs better, although it cannot be established to what extent this is a statistically significant difference.
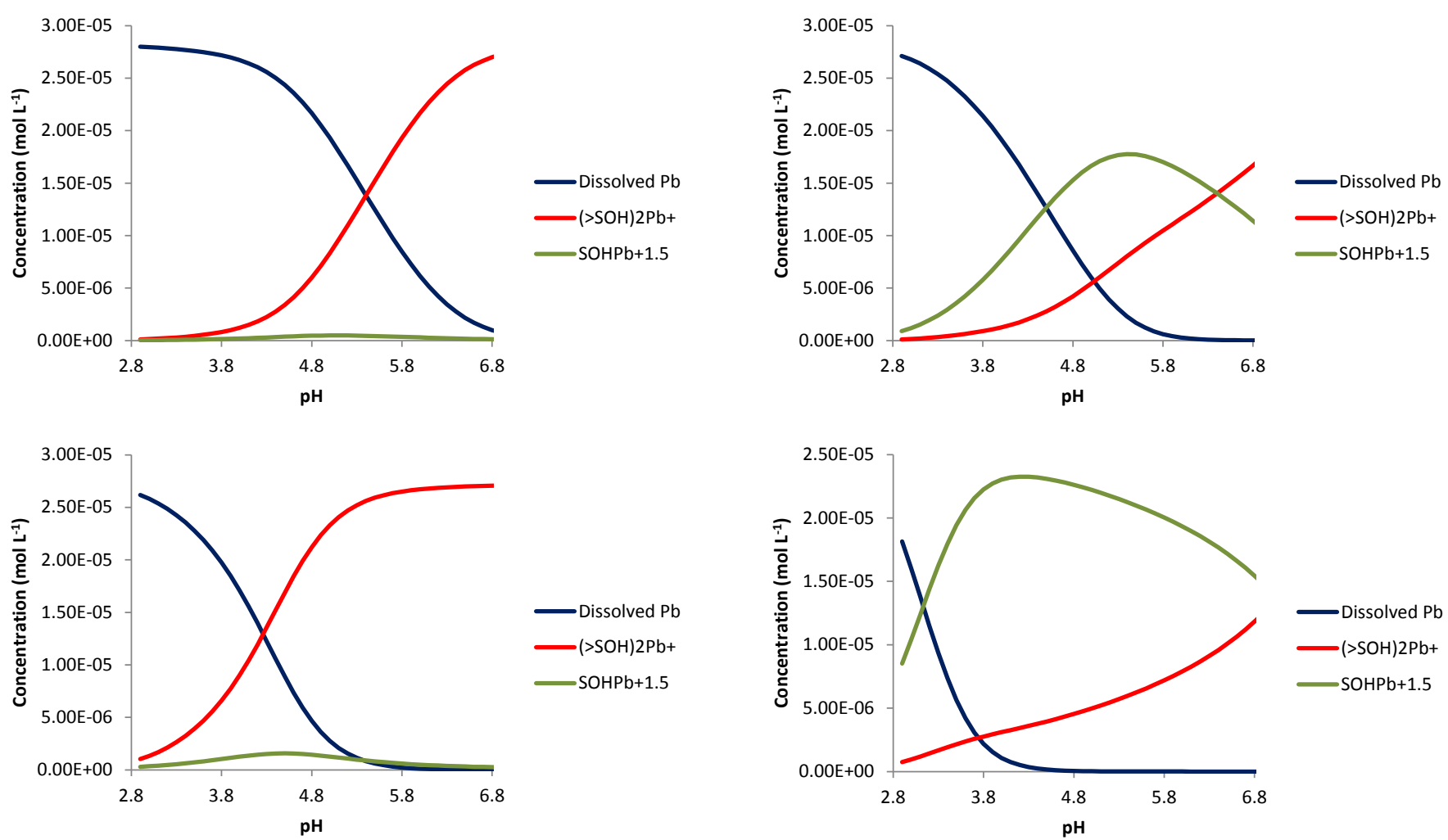

Fig. S6. Concentrations of $\mathrm{Pb}$ species as a function of $\mathrm{pH}$. Upper row: systems with $\mathrm{Pb}=28.2$ $\mu \mathrm{M}, \mathrm{Fe}=0.3 \mathrm{mM}$. Lower row: systems with $\mathrm{Pb}=28.2 \mu \mathrm{M}, \mathrm{Fe}=3 \mathrm{mM}$. The figures in the left column are for systems without $\mathrm{P}$, the right-hand column shows systems that contain 63 $\mu \mathrm{M}$ (upper right) or $630 \mu \mathrm{M}$ (lower right).

In Fig. S6 it is seen that the systems without $\mathrm{P}$ has a very small contribution from monodentate complexes, which was one of the requirements for the model. On the right it is also seen that the monodentate complexes predominate the sorbed $\mathrm{Pb}$ in systems that contain P. At $\mathrm{pH} 4.0$ (for which $\mathrm{pH}$ an EXAFS spectrum was recorded) the contribution from bidentate complexes to the overall sorbed $\mathrm{Pb}$ was below $10 \%$.

\section{$\underline{\text { Discussion and conclusion }}$}

This exercise shows that it may be possible to explain the results with Model 3, in which no ternary complexes are formed at all. Instead the greatly increased $\mathrm{Pb}^{2+}$ adsorption in the presence of $\mathrm{P}$ could be explained by the increased role of a monodentate complex, which is insignificant in systems with only $\mathrm{Pb}^{2+}$, but important in systems with $\mathrm{PO}_{4}$. There are, however, two apparent problems with this model:

1. It does not accurately describe the enhanced $\mathrm{PO}_{4}$ adsorption in the presence of $\mathrm{Pb}^{2+}$, whereas the ternary surface complex model predicts $\mathrm{PO}_{4}$ more successfully. However, this observation is based only on one data set. More data sets need to be collected to confirm this observation. 
2. The equilibrium constant of the monodentate complex cannot be verified experimentally, as it is not observed in a pure $\mathrm{Pb}-\mathrm{Fe}$ system. The basis for the assumed affinity of the monodentate complex is therefore shaky.

None of these arguments is sufficiently strong to discount model 3 at the present stage, and therefore it needs to be taken into consideration seriously. To obtain more evidence on what model that is correct, we suggest using additional EXAFS spectroscopy as well as ATR-FTIR spectroscopy.

Similar conclusions can be drawn for the $\mathrm{Cu}-\mathrm{Fh}$ systems with $\mathrm{PO}_{4}$. However, with our data it is more difficult to evaluate model 1 for these, for two reasons: (i) the overall weaker $\mathrm{Cu}-\mathrm{PO}_{4}$ interaction found for these systems, and (ii) the absence of strong $\mathrm{Cu}-\mathrm{PO}_{4}$ interactions for the system with the highest $\mathrm{Cu} / \mathrm{Fe}$ ratio, for which $\mathrm{PO}_{4}$ may have been affected by $\mathrm{Cu}$. 